2017-12

\title{
Annual prediction of shoreline erosion and subsequent recovery
}

Mikhalenko, Natalia

http://hdl.handle.net/10026.1/10259

10.1016/j.coastaleng.2017.09.008

Coastal Engineering

Elsevier

All content in PEARL is protected by copyright law. Author manuscripts are made available in accordance with publisher policies. Please cite only the published version using the details provided on the item record or document. In the absence of an open licence (e.g. Creative Commons), permissions for further reuse of content should be sought from the publisher or author. 


\section{Annual Forecasting of Extreme Shoreline Erosion and Subsequent Recovery}

Affiliations:

1. Coastal Processes Research Group, Plymouth University. (Corresponding Author)

2. Water Research Laboratory, School of Civil and Environmental Engineering, UNSW Sydney.

\section{Abstract}

Prediction of the potential impact of an extreme storm-sequence on coastal resilience and the subsequent rate of post-storm recovery is a fundamental goal for coastal scientists, engineers and managers alike. This paper presents a methodology for forecasting shoreline change over annual time-scales, including the prediction of the potential impact of storm sequences and the subsequent post-storm recovery. The methodology utilises an archive of measured or modelled wave data to produce multiple $\left(\approx 10^{3}\right)$ synthetic hydrodynamic forcing time-series to drive an equilibrium shoreline model in a Monte Carlo simulation. A Generalised Extreme Value (GEV) analysis is conducted on the resulting shoreline forecasts in order to evaluate the magnitude of shoreline displacements for predefined return probabilities. Three shoreline displacement bands are defined in a 'traffic light' system, to aid the interpretation of results; a green (normal) band characterising shoreline responses within the typical annual recurrence probability, an amber (high) band defining events with recurrence probabilities outside the annual recurrence threshold but within 1/100 of this value, and a red (extreme) band designed to encompass the limit of the shoreline forecasts. The methodology was tested on two field sites with distinctly contrasting wave climates and tidal regime. The first was Perranporth in the UK with a strong seasonal variability in both the wave climate and shoreline response. The second was Narrabeen, Australia, with a much smaller seasonal variability and more storm-dominated wave climate and shoreline response. In both cases an equilibrium shoreline model (ShoreFor) was calibrated using measured shoreline data and complementary wave data. The forecasting methodology was found to be mildly sensitive to the temporal range of the wave data used, with at least 15-years of data required to achieve consistent classification of the magnitude of storm erosion and recovery. Two extreme storm sequences were targeted to test the forecasting methodology, the Pasha Bulker storm sequence recorded at 
32 Narrabeen in June 2007 and the extreme storm sequence which impacted the UK during the winter 33 period of 2013/14. All wave and shoreline time-series recorded in this period were left unseen in 34 model calibrations and subsequent forecasts, in order to provide a rigorous test of the methodology.

35 In all cases the forecasting approach presented here was able to predict both storm erosion and 36 subsequent recovery and give a clear indication of the intensity of the shoreline displacement. Both 37 storm sequences studied had shoreline displacements with occurrence probabilities of $\approx 1 / 1200$ and 38 rapid post-storm recovery rates. The impact of extreme storms on shoreline recession and 39 subsequent post storm recovery is predictable at these energetic cross-shore transport dominated 40 sites, promising the potential for a new coastal management tool.

\section{Introduction}

43 Arguably the 'holy grail' for coastal scientists and engineers is to derive sufficient knowledge and 44 understanding of coastal systems to be able to forecast coastal erosion and accretion with a level 45 of confidence and lead time to permit effective coastal management decisions to be made regarding 46 the use, development and protection of coastal environments. Important coastal management 47 questions addressed here are: What are the potential storm impacts on the coastline? Will the coast recover from the prior violent storm(s) and how long will this recovery take?

50 In spite of the development of sophisticated process models with demonstrable skill in hindcasting 51 coastal hydrodynamics, the complexities and non-linearity of sediment transport and 52 morphodynamic processes mean that our ability to hindcast (let alone forecast) coastal erosion and 53 recovery at a seasonal time-scale remains limited at the present time. Indeed, our ability to forecast

54 beach recovery with physics-based models has proved to be particularly illusive [1, 2]. The 55 forecast horizon of these detailed process-models is limited not only by computing speed but also 56 their long-term stability and model skill [3].

Common coastal state indicators used by managers to assess the current health of the coastline and 59 resilience to coastal erosion and flooding frequently include some measure of beach volume or 60 shoreline position $[4,5]$. So, in this contribution, a 'simpler' methodology appropriate to 61 forecasting these indices is investigated, rather than the complex time-varying and 3-dimensional 62 structure of the beach surface. Although shoreline prediction is the focus of this study, intertidal 
63 beach volumes have been shown to be coherent with shoreline evolution $[6,7,8]$ and therefore the 64 approach developed here is expected to be transferable.

66 Recently, models of 'reduced complexity' $[6,10]$ have been shown to provide skilful hindcasts of 67 coastal change on both cross-shore $[11,12,13,14,15]$ and longshore transport dominated $[16,17$, $6818,19,20]$ coastlines. The simplicity and stability of such models unlocks the exciting potential 69 for much longer-term (months-years-decades) hindcasts and even forecasts of coastal change.

71 Skilful hindcasting of coastal evolution with known forcing conditions is a necessary precursor to 72 forecasting of future coastal change. Short-term deterministic forecasts with a 5- to 10-day 73 prediction horizon can be achieved with the aid of accurate forecasts of wave forcing derived from 74 physics-based weather models [21]. However, at prediction horizons in excess of this one must 75 fall back on climatological/statistical approaches to forecasting. The latter approach is the subject 76 of the present paper, which develops forecasts up to (and potentially beyond) one year. 77 Climatological approaches can be particularly skilful in predicting weather, when there is a strong, 78 coherent seasonal variability, for example, annual fluctuations in air temperature or wind speed. 79 Although there are some examples of climatological shoreline forecasting (e.g. [22]), this research 80 area is still in its infancy.

82 In this contribution multiple synthetic wave time series are derived from a pool of measured data 83 and subsequently used to force a Monte Carlo shoreline simulation using a simple equilibrium 84 model. Monte Carlo methods have been implemented for the prediction of shoreline change in the 85 past (e.g. [12, 23, 24]), however the approach taken here is somewhat different. A robust statistical 86 generalised extreme value (GEV) analysis is used to predict the magnitude of shoreline 87 displacement for pre-defined recurrence probabilities. Details of the two field sites with contrasting 88 wave climates and tidal regimes, which are used to test the forecasting methodology are given is 89 section 2. This is followed by an overview of the forecasting methodology in section 3, including 90 a description of the shoreline model, the method of generating multiple synthetic wave records 91 using measured or modelled data and finally the method of generalised extreme value analysis 92 (GEV), which gives shoreline displacements for specified recurrence probabilities. In section 4 the 93 results of this procedure are presented for both the storm and recovery period of two major storms 
94 experienced at two contrasting sites. The finding of this research and future developments are 95 summarised in sections 5.

\section{2. Site Description}

98 Two extensive shoreline datasets and complementary wave measurements at highly contrasting 99 environments (Table 1) are used to provide a rigorous test of a shoreline forecasting methodology.

100 Both environments are energetic, cross-shore transport dominated, swash-aligned coastlines, but 101 each has very different temporal variability in their wave climate and shoreline response. 102 Specifically, the two sites are: Perranporth, with a highly seasonal wave climate, located on the 103 exposed Atlantic west coast of Cornwall in the UK [25] and Narrabeen, with a storm dominated 104 wave climate, located on Sydney's northern beaches on the eastern seaboard of Australia [26], 105 (Figure 1). A summary plot showing the seasonal succession of ensemble-averaged parameters 106 that will be subsequently used to force the shoreline model and the measured shoreline responses 107 for both Perranporth and Narrabeen are shown in Figure 2. The forcing parameters include wave 108 power and dimensionless fall velocity, $\Omega=H_{b} / \omega T$ [27], where $H_{b}$ is the breaker height, $\omega$ is the fall 109 velocity of the beach sediment and $T$ is the peak wave period.

111 The Perranporth wave data in Figure 2 is based on a 65-year record of hourly Wave Watch III 112 modelled offshore (73 m depth) significant wave height and period data for the location of the 113 Sevestones Lightship [28] and a complementary time-series of the cross-shore position of the 114 shoreline, extracted from GPS surveys conducted over an 8-year period [29]. The Narrabeen data 115 used here includes a 36-year record of hourly offshore wave statistics, measures at Sydney's wave 116 rider buoy (depth $74 \mathrm{~m}$ ) and a complementary 8-year time-series of shoreline displacements. For 117 consistency, shorelines at both sites were centred on the mean high-water contour line, which was 118 averaged over a $400 \mathrm{~m}$ longshore distance and sampled at monthly time intervals.

$120 \quad 2.1$ Perranporth, UK

121 Perranporth, is a $3.5 \mathrm{~km}$ long, macrotidal (mean spring tidal range $6.5 \mathrm{~m}$ ) beach situated on the 122 northern coast of the UK's southwest peninsula (Figure 1a). It is directly exposed to normally 123 incident, energetic and highly seasonal swell waves generated by anticyclones propagating on a 124 general westerly track across the northern Atlantic Ocean. This seasonality in the wave climate is 
125 shown clearly in the monthly-averaged wave power, where energetic, long-period swell waves

126 arriving during the November to January are $\approx 5.5$ times higher than the (June-August) summer

127 months (Figure 2a).

129 Beach sediments are comprised of quartz sand with average $D_{50}$ of $0.33 \mathrm{~mm}$ and a fall velocity of

$1300.04 \mathrm{~m} / \mathrm{s}$ [30]. Monthly-averaged dimensionless fall velocities at Perranporth are in the range (4.5-

131 6) indicating intermediate to dissipative beach states which are consistent with observations. The

132 modal classification at Perranporth is low-tide bar and rip according to the classification of

133 Masselink and Short [31]. However, winter periods are often typified by highly dissipative beach

134 states.

136 The shoreline response at Perranporth (Figure 2e) shows high variance at annual time-scales, with 137 shoreline erosion commonly evolving smoothly over the November to February fraction of the 138 year in response to a succession of erosive storms, rather sharp step-like displacements relating to

139 individual storm events (Figure 2). During this winter storm season the horizontal displacement of 140 the mean high water contour can be very large, exceeding $70 \mathrm{~m}$. Beach recovery begins in late 141 March and proceeds at a much slower rate $(\approx 1 / 4)$ than the erosion, often persisting until October.

143 Interannual variability in the wave climate is dominated by the North Atlantic Oscillation index 144 with more positive values being indicative of stronger westerly winds and waves [29], although 145 the direct link with shoreline erosion and morphology remains unsubstantiated [32].

$147 \quad 2.2$ Narrabeen, Australia

148 Narrabeen is a microtidal (mean spring tidal range $\approx 1.5 \mathrm{~m}$ ), $3.5 \mathrm{~km}$ long, embayment, situated on 149 Sydney's northern beaches (Figure 1b). The Narrabeen wave climate is dominated by two 150 principle components. The first is a moderate to high energy condition which prevails from the $151 \mathrm{~S} / \mathrm{SE}$ with a mean period and wave height of $T_{\mathrm{p}} \approx 10 \mathrm{~s}$ and $H_{\mathrm{s}} \approx 1.6 \mathrm{~m}$ respectively and is generated 152 by mid-latitude cyclones propagating over the Tasman Sea [33, 34]. The second component are 153 storm events $\left(H_{\mathrm{s}}>3 \mathrm{~m}\right)$ which represent $6 \%$ of the observed wave field [35]. Storms vary 154 seasonally, with most storms occurring in winter (39\%), fewest storms occurring in summer (12\%) 155 and transitional periods observed in autumn (26\%) and spring (23\%) [34]. Winter storms are 
156 characterized by high power waves from a S/SE direction generated by mid-latitude cyclones from

157 the south and east coast low pressure systems. Notice however that the maximum monthly158 averaged offshore wave power at Narrabeen is only a third of that observed at Perranporth (Figure

$1592 \mathrm{~b}$ and $\mathrm{c}$ ). The summer wave climate is dominated by NE short period waves generated by a local 160 sea breeze [33]. Interannual variability in the Sydney wave climate is influenced by the Southern

161 Oscillation Index, in particular the La Niña phase is associated with an increase in storm frequency 162 and duration with a dominant NE/E direction, whereas El Niño phase is characterized by milder $163 \mathrm{SE} / \mathrm{S}$ wave conditions [36, 34].

165 Narrabeen is characterised by coarser sand than Perranporth $\left(D_{50} \approx 0.4 \mathrm{~mm}\right)$, and monthly-mean 166 dimensionless fall velocities $(\Omega=3.4-3.8)$ that are indicative of the range of intermediate beach 167 states that are observed, including both welded and detached bar states. Interestingly, 168 dimensionless fall velocities are lowest in the Austral winter even though winter waves are more 169 energetic. This factor relates to the longer wave periods associated with the winter swell.

171 The surfzone width at Narrabeen is relatively narrow compared to Perranporth, leading to efficient 172 sediment transport between the beach face and sandbars and more rapid shoreline displacements, 173 which typically proceed at monthly (storm) time-scales. In spite of this rapid shoreline response 174 there is also a significant seasonal signal at Narrabeen, with erosion during the months of April to 175 July and beach recovery predominantly in the subsequent November to March period (Figure 2f). 176 Maximum shoreline displacements at Narrabeen are half $(\approx \pm 20 \mathrm{~m})$ that observed at Perranporth 177 and the seasonal range less than a quarter $(\approx \pm 10 \mathrm{~m}$, Figure $2 \mathrm{e}$ and $\mathrm{f})$. Splinter et al., [15] 178 characterised the relative seasonal to storm dominance by the ratio of the yearly- and monthly179 average standard deviations in dimensional fall-velocity, whereby values significantly greater than 1801.0 typify highly seasonality. The storm dominance at Narrabeen is again highlighted by the 181 observed value of $\sigma_{\Omega 365} / \sigma_{\Omega 30}=1.07$, which is some $13 \%$ lower than that observed at Perranporth 182 (1.22). Due to this storm dominance it might be expected that the shoreline dynamics of this Pacific 183 east coast site will be the most challenging to forecast meaningful shoreline responses due to the 184 episodic nature of the storms. 
187 In this section, we focus on two notable extreme storm sequences recorded at Perranporth and

188 Narrabeen. At Perranporth the extreme storms in the November-February period of 2013/14

189 produced the most powerful sequence of waves observed in the past 65 -years causing over $70 \mathrm{~m}$

190 of shoreline recession. Masselink et al., [37] reported that 22 storms (each $>1 \%$ exceedance in

191 offshore significant wave height) were observed in this period. At Narrabeen the model will be

192 tested on a powerful sequence of extreme storms recorded during the La Niña year in June 2007,

193 which caused the bulk tanker Pasha Bulker to run aground on a beach north of the site and resulted

194 in over $35 \mathrm{~m}$ of shoreline recession at Narrabeen [38], hereafter referred to as the 'Pasha Bulker

195 storm'.

\section{3. Forecasting methodology}

198 This section briefly describes the equilibrium shoreline model that is used to derive the shoreline

199 forecasts. A detailed description of the model is avoided here and instead the Reader is directed to

200 Davidson et al., [39] and Splinter et al., [15] for a more thorough description and validation of the 201 model. After the brief description of the model, details of the calibration and validation are given.

202 This is followed by a description of the simulation of the synthetic wave forcing parameters that 203 are used to force the shoreline model in a Monte Carlo fashion and form the basis of the generalised 204 extreme value analysis.

\subsection{ShoreFore - Model Description}

207 The shoreline change with time is expressed as a function of the incident wave power $(P)$ and the 208 disequilibrium in the dimensionless fall velocity $\Delta \Omega$.

$209 \frac{d x}{d t}=c^{ \pm} P^{0.5} \Delta \Omega$

210 Here $c$ is the response rate coefficient that controls the magnitude of the shoreline response per 211 measure of wave power $\left[\mathrm{m} /(\mathrm{W} / \mathrm{m})^{0.5}\right]$. The response rate parameter takes different values 212 depending on whether the shoreline is eroding or accreting. The sign of the shoreline displacement 213 is controlled by the disequilibrium in the dimensionless fall velocity $(\Delta \Omega)$, which is given by:

$214 \Delta \Omega=\frac{1}{\sigma}\left(\Omega_{\phi}-\Omega\right)$ 
215 Here $\Omega$ is the instantaneous dimensionless fall velocity and $\Omega_{\phi}$ is a weighted average of the

216 antecedent dimensionless fall velocity by the following weighting function [40].

$217 \Omega_{\phi}=\left[\sum_{i=1}^{2 \phi} 10^{-i / \phi}\right]^{-1} \sum_{i=1}^{2 \phi} \Omega_{i} 10^{-i / \phi}$

218 and $\sigma$ is the standard deviation of $\left(\Omega_{\phi^{-}} \Omega\right)$, such that $\Delta \Omega$ has unit standard deviation and primarily

219 controls the sign of the shoreline change. The model predicts erosion when incident waves are

220 steeper than the weighted average (antecedent) conditions and visa-versa for accretion. A strong

221 hysteresis in the shoreline behaviour is implicit in this model, whereby future change is highly

222 dependent on the antecedent forcing conditions. Thus, forecasts of shoreline position are not just

223 a function of the future forcing conditions, they are also strongly influenced by the antecedent

224 conditions. The parameter $\phi$ is measured in days and controls the decay in the weighting function

225 which has a value of one at the prediction time, decaying to 0.1 and 0.01 at $\phi$ and $2 \phi$ days

226 respectively before the prediction time. The value of $\phi$ effectively controls the frequency of the

227 shoreline response with values $>>10^{2}$ days producing a dominantly seasonal shoreline response

228 (given some seasonality in the observed wave climate), typical of dissipative beaches, whilst

229 values $<10^{2}$ days produce a higher frequency storm response, typical of more intermediate beaches

230 [15]. Note that for a given site with consistent grainsize, the variability in the forcing parameters

$231\left(P\right.$ and $\Omega$ ) is controlled only by hydrodynamic variables $\left(H_{b}\right.$ and $\left.T\right)$. We require synthetic values

232 of these parameters, which reflect the observed seasonal statistics of the wave field, in order to 233 generate the shoreline forecasts.

235 3.2 Model Calibration

236 Figure 3 shows the wave power time-series alongside the respective model calibrations and 237 validations for both the Perranporth and Narrabeen data sets. Here the two major storm sequences 238 have been omitted from the model calibration and have been used here to validate the models 239 capacity to hindcast two major storm events, using measured forcing parameters. These storms are 240 the Pasha Bulker storm sequence in June 2007 at Narrabeen and the extraordinary storm sequence 241 which struck the exposed energetic coastlines of the north Atlantic during the winter of 2013/14.

242 These storms will be used later to test the forecasting method and the true wave forcing for these 
243 periods will remain unseen for both the model calibration and the later forecasts in order to provide

244 a rigorous test of the methodology.

246 As shown in Figure 3, model hindcasts are highly skilful at matching observations for both 247 calibration ( $r=0.92$ Perranporth; $r=0.87$ Narrabeen) and validation $(r=0.98$ Perranporth; $r=$ 2480.89 Narrabeen) subsets of the data at both sites. It is noted that the model optimised $\phi$ values for 249 both sites are 15 days for Narrabeen, typical values for a storm-dominated intermediate beach, in 250 contrast to 450 days for Perranporth, in keeping with this contrasting site exhibiting a seasonally251 dominated dissipative beach.

\section{$253 \quad 3.4$ Generating Synthetic Time-series}

254 A quasi-Monte Carlo simulation method is adopted here for forecasting the shoreline climatology.

255 A similar method of shoreline forecasting was suggested by Davidson et al., [12], who 256 implemented the method of Borgman and Scheffner [41] to generate synthetic wave series based 257 on the monthly, statistical variability in wave height, period and direction in the measured wave 258 field. This contribution moves on from this work by implementing a different method of synthetic 259 wave generation, and the application of a more sophisticated GEV analysis of the model output.

261 Generation of synthetic waves involves the assembly of a large number of forcing time-series, 262 used later to drive the shoreline model. The key forcing parameters for the ShoreFor model are 263 wave power $(P)$ and dimensionless fall velocity $(\Omega)$ time-series. These synthetic series must reflect 264 the measured or modelled statistical properties for the prediction site. Each of the resulting forcing 265 series are used to generate a shoreline forecast using the calibrated ShoreFor model detailed in the 266 previous section. Typically, $N=10^{3}$ synthetic time-series are generated for the Monte Carlo 267 simulations. The number of simulations is easily extended given the computational efficiency of 268 the method, but $10^{3}$ estimates was found to provide stable, consistent forecasts. A rigorous 269 statistical GEV analysis of the resulting shoreline data is then used to compute the magnitude of 270 both shoreline accretion and erosion corresponding to specified recurrence probabilities.

272 In the present contribution, we restrict our forecast horizon to one year. This is done because a 273 meaningful multiyear forecast requires additional knowledge of the likely inter-annual variability. 
274 The forecasting methodology used here does not include this, although work is currently in 275 progress to extend the predictions in this direction.

277 A pool of either modelled (i.e. Perranporth), measured or a combination of these (i.e. Narrabeen) 278 wave data is used to generate new times series of both $P$ and $\Omega$. This is done by building multiple, 279 annual time-series of $P$ and $\Omega$ on a month-by-month basis, by selecting an equivalent month of 280 data from the available wave data corresponding to a randomly selected year. As each month is 281 incremented a different random year is selected each time. This method is simple but very effective 282 in conserving the monthly evolution of the statistical properties in the observed wave field, as well 283 as accurately preserving the sequencing of waves. The size of the wave data pool for Perranporth 284 and Narrabeen examples were 63 years and 36 respectively. The impact of the size of the data pool on predictions is examined later in this section.

In order for the test to be rigorous, the data pool used to generate the synthetic time-series must exclude the forecasting period, even if the data are in fact known (i.e. hindcast). The data pool must also be consistent with the wave data used to calibrate and validate the model (same source or statistically similar).

292 Future modifications of the wave climate, due to climate change for example, are not included in 293 these tests; a reasonable assumption for an annual time-scale of the forecasts presented here. It is 294 assumed that the wave data $2 \phi$-years prior to the prediction date $\left(t_{0}\right)$ is known (equivalent to the 295 maximum width of filter function window, equation 3) in order to evaluate the appropriate 296 antecedent conditions, (Figure 4). Each of the new synthetic time-series are concatenated on the 297 end of these $2 \phi$-years of observed data (Figure 4). It is the combination of the known antecedent 298 conditions and unknown future wave conditions which will determine the nature of the forecast.

300 Figure 5 shows an example of the resulting $10^{3}$ Monte Carlo shoreline predictions corresponding 301 to the synthetic forcing series. Notice that these simulations were started on the $1^{\text {st }}$ October 2013, 302 just prior to the extreme storms at Perranporth. Thus, the distribution shows an initial tendency for 303 erosion (negative mean displacements), with recovery beginning in April and returning to near 304 zero mean displacement by the end of the year. Notice also the spread in shoreline predictions for 
each month of the year, a distribution that will be characterised by the Generalised Extreme Value

306 (GEV) analysis detailed in the next section.

\subsection{Generalised Extreme Value (GEV) Analysis}

309 Here we extract from the shoreline prediction matrix the independent, extreme values of shoreline 310 position (for both erosion and accretion) for each simulation, corresponding to a regular time 311 interval in the forecasts. Care is taken to use only unique shoreline series as the random generation 312 method for the forcing series used here can potentially produce identical forcing and therefore 313 replica shorelines. Typically, monthly intervals are used here, although this window duration can 314 easily be varied. These monthly extremes from each of $10^{3}$ simulations are plotted as histogram 315 and a GEV probability distribution function (PDF) is fitted to the data. The GEV analysis used 316 here focusses on accurately fitting the tails (extremes) of the distribution (rather than the peaks) 317 and allows the data to instruct which of three distribution options is most appropriate to the 318 observations [42]. These options are controlled by a shape function $k$ which dictates the decay 319 structure at the limits of the distribution. Here an exponential decay is selected for $k=0$ (e.g., 320 normal, Gumbel, [43]), a polynomial for $k>0$ (e.g. student's t-test, Fisher and Tippett, [44]), or $k<0$ 321 if the extreme is finite (e.g. Weibull, [45]). The form of the extreme value distribution PDF is:

324 or

$y=f(x \mid k, \mu, \sigma)=\left(\frac{1}{\sigma}\right) \exp \left(-\left(1+k \frac{(x-\mu)}{\sigma}\right)^{-\frac{1}{k}}\right)\left(1+k \frac{(x-\mu)}{\sigma}\right)^{-1-\frac{1}{k}} \quad$ for $k \neq 0$

327 Here $\mu$ is the mean and $\sigma$ is the standard deviation. Conveniently, users of Matlab will find that 328 the statistical toolbox has a useful function for achieving the optimised fit to observations. The 329 methodology was found to be most successful and very robust when fitting to the negative of the 330 observed shoreline distribution (i.e. negative accretion and positive erosion) and then accounting 331 for the change in sign later (reverting to the positive accretion and negative erosion convention) in 332 the subsequent analysis and figures. 
334 The classification of appropriate thresholds in order to define storms or events is non-trivial and 335 usually effects the ultimate prediction of return magnitudes and periods of the series being 336 analysed [46]. Additionally, wave and shoreline time-series are fundamentally different, for 337 example extreme storms may have annual occurrences of $\mathrm{O}\left(10^{1}\right)$, occurring in multiple months, 338 whereas shoreline series typically have single annual maxima/minima occurring in just one month

339 of the year. This fact means that it is potentially erroneous to borrow established thresholding 340 techniques which have been established for wave data and apply them directly to morphological 341 time-series.

343 As is the case with storm-wave thresholds, magnitude-based thresholds for shoreline displacement 344 would necessarily differ from site-to-site, depending on the size of the observed shoreline 345 variability. Here we seek a common methodology that will be equally applicable to all sites, 346 irrespective of the size of the observed shoreline variability. For this reason, a probability of 347 occurrence threshold has been applied to the shoreline forecasts. Notice also, that unlike wave 348 forecasts, which seek to apply only a storm threshold to isolate the highest waves, a bi-directional 349 threshold is sort here to separate normal from high erosion and accretion events. Since we are 350 dealing here with both erosion and accretion, it is also inappropriate to define shoreline 351 displacements above threshold as storms, therefore we will refer to shoreline displacements which 352 exceed threshold value as events in the following text.

354 This methodology defines three erosion and three accretion bands using the cumulative GEV PDF 355 function, which has been fitted to the model forecast data. Erosion and accretional bands are 356 defined by $\operatorname{Pr}$ and $(1-P r)$ respectively, where $\operatorname{Pr}$ is the probability threshold for the band. Here 357 we characterise the intensity of the cross-shore shoreline displacements with a colour-coded traffic 358 light system. These three bands are normal (green), high (amber) and extreme (red) and described 359 in detail below:

360 1) Normal (green): This band includes predictions which typify annual shoreline 361 displacements. Predictions in this band are not characterised as events and have recurrence 362 probabilities constrained by the event probability ( $\left.P r_{\text {threshold }}\right)$, whereby, the 363 erosion/accretion limits of this band are: $P r_{\text {threshold }}<$ Normal band limits $<1-P r_{\text {threshold. }}$ 
2) High (amber): These are predicted shoreline displacements which are classified as events having recurrence probabilities lying outside of the green band but constrained within: $P r_{\text {threshold }} / 100<$ High band limits $<1-\left(P r_{\text {threshold }} / 100\right)$. Thus, the outer limits of this band typify the probability of a $1 / 100$ recurrence event.

3) Extreme (red): This band defines extreme events with probabilities outside of the high band but encompassing the extremes of the predictions. In these simulations, this condition was satisfied by setting the erosion/accretion limits at: $P r_{\text {threshold }} / 10^{7}<$ Extreme band limits $<1$ $-\left(P r_{\text {threshold }} / 10^{7}\right)$. Where the factor of $10^{7}$ is an arbitrarily selected high value.

373 The erosion and accretional bands are separated by the mean (central tendency, $\mu$ ) of the shoreline 374 forecasts, which is also a bi-product of the GEV PDF fit to data (equations 4 and 5). Much like 375 any other extreme value analysis the traffic light system used here is sensitive to the threshold 376 value ( $\left.P r_{\text {threshold }}\right)$. Here we have elected to use a recurrence probability rather than an amplitude 377 threshold on the grounds that this methodology should be less site specific. Nonetheless, the 378 methodology is sensitive to the value of event threshold selected. We examine this sensitivity in 379 the results section by varying the threshold between one month per year $\left(P r_{\text {threshold }}=1 / 12\right)$ and one day per year $\left(P r_{\text {threshold }}=1 / 365\right)$.

The inverse of the fitted GEV PDF is used to return shoreline positions corresponding to the pre383 mentioned probability values and define the limits of these three bands. Example histograms for 384 Monte Carlo shoreline forecasts, extracted from the data in Figure 5 for the time intervals marked 385 a-f are shown in Figure 6 (also labelled a-f). The traffic light coding and PDF fits to the data are 386 also shown in these figures. Notice how well the GEV PDFs fit the tails of the distributions (amber 387 and red bands). Encouragingly, the pre-mention bands encapsulate both the extremes of the data 388 and the range shoreline displacements categorised as normal correlate well with the observed time389 series. 3.6 Sensitivity of model forecasts to the duration of the wave pool

392 Figure 7 shows an example predictions for the severe 2013/14 storms observed at Perranporth, 393 UK. The GEV PDF and traffic light system have been presented here as a background for the 394 observed data. Note that the probability threshold defining an event $P r_{\text {threshold }}$ has been set to $1 / 12$ 
395 in these examples. This is annual forecast starting at the beginning of October 2013 and running 396 through the extreme storm sequence and subsequent recovery period. Also presented in Figure 7, 397 is the sensitivity of the forecasts to the total duration of the wave data pool used to generate the 398 synthetic forcing for the model. Here we progressively reduce the data pool at Perranporth from 399 60-years to just 10-years prior to the sample date. It can be seen from these plots that in all cases 400 the observations fall within the predicted limits of the extreme (red) band.

402 The forecast which utilised 60-years of wave data (Figure 7a), shows that the shoreline response 403 to the winter storms is on the boundary between the high-range and extreme range with an expected 404 event recurrence probability close to $1 / 100$, for this prediction starting 2-months prior to main 405 shoreline recession. This classification remains consistent within the uncertainty of the data, for 406 wave pool sizes of at least 20-years but changes to an extreme classification (red) for a wave pool 407 size of just 10 years. Based on this and other tests (not shown) the authors suggest that the wave 408 pool size should exceed 15-years in order to achieve consistent forecast classifications, although a 409 firm conclusion on this point will probably require experimentation at additional sites.

411 4. Results

\subsection{Perranporth, UK}

413 Figure 8 shows both the forecast and measured shoreline impact and subsequent recovery of the 414 2013/14 winter storms at Perranporth $\left(P r_{\text {threshold }}=1 / 12\right)$. In order to capture a complete season of 415 recovery-erosion-recovery, forecasts start 7-months prior to the main storm impacts on the $1^{\text {st }}$ May 4162013 during the beach recovery phase and proceeds with start times $\left(t_{0}\right)$ incrementing in two-month 417 intervals through the storm and up to the start of the post-storm recovery. In doing so we are able 418 to answer two key coastal management questions, namely: Can we predict the likely impact of the 419 next extreme storm sequence? And, can we forecast beach recovery after the impacts of an extreme 420 storm sequence?

422 Figure 8a shows the shoreline forecast during the recovery period, prior to the main storm. The 423 forecast predicts a narrow range of potential shoreline projections over the coming six-months. It 424 is not until the onset of the winter storms, when there is a tendency for erosion that the predicted 425 range in shoreline responses widens significantly. Inspection of the measured data in this plot 
426 shows that shoreline recovery in this example (Figure 8) is slow initially, remaining in the lower-

427 amber range during the period leading up to the storms, but reaching the low-normal (green) range

428 by December 2013.

430 Pre-storm shoreline positions were at the shoreward-extreme of the normal range prior to the 431 storms (i.e. somewhat eroded for the time of year). In all cases the data are effectively captured 432 within the prediction band and the range of the predictions is not so excessive as to be of limited 433 value. This example (Figure 8a) shows that for this seasonally dominated site, shoreline recovery 434 is indeed predictable and can be forecast.

436 The classification of the observed 2013/14 storm impact (see arrow in Figure 8a), starting 11 437 months before the maximum observed erosion is extreme (red). This rating has an event return 438 probability of less than $1 / 100$. This extreme (red) classification of the storm reduces to the outer 439 limit of the high (amber) band, seven months prior to the maximum storm erosion $t_{0}=1^{\text {st }}$ 440 September 2013 (Figure 8c). This is likely due to the fact that the beach levels were already 441 uncharacteristically low for the time of year, just prior to the main storm sequence. This 442 classification then remains consistent right up to the start of the main storm sequence starting in 443 November 2013 (Figure 8d). These results (and threshold selection, $P r_{\text {threshold }}=1 / 12$ ), suggest that 444 the Perranporth storm sequence of $2013 / 14$ had an event return probability of $\approx 1 / 100$. This 445 classification even remains consistent through the storm (Figure 8e).

447 The post extreme-storm recovery is predicted after the 2013-14 storms, starting $t_{0}=1^{\text {st }}$ March 2014 448 in Figure 8f. It can be seen in this second recovery example, that once again, the forecast is tight 449 and accurate. Unlike the pre-storm recovery (Figure 8a), the post recovery is much more rapid, 450 proceeding in the upper-amber range. This was somewhat unexpected as the offshore survey data 451 (not included here) showed that the eroded beach sand had been moved to an offshore bar, located $4521 \mathrm{~km}$ offshore of the high-tide shoreline position. This extreme translation of sand does not seem 453 to have stunted beach recovery at all. Notice however, that there is quite a bit of uncertainty in the 454 measurements, represented by the error bars in the data during this recovery phase as the beach 455 gets more 3-dimensional in the longshore direction as the sand moves from the offshore sandbar 456 towards beach. Again, Figure 8f supports the notion that beach recovery is indeed predictable at 
457 this site. Notice also that the methodology used here may forecast different outcomes for the same 458 month in different years, due to importance and potentially different antecedent hydrodynamic 459 conditions.

\section{$\underline{4.2 \text { Narrabeen, Australia }}$}

462 Perhaps a more challenging test for this forecasting methodology is application to a distinctly 463 storm dominated wave climate, with a weaker seasonal signal, where shoreline responses are more 464 rapid. The Narrabeen dataset provides the opportunity to do this. Like the previous Perranporth 465 example, Figure 9a starts during the natural recovery-phase on the $1^{\text {st }}$ October 2006, prior to the 466 Pasha Bulker storm sequence. An identical methodology to that used in the previous example at 467 Perranporth has been applied here to an extreme storm sequence at Narrabeen $\left(P r_{\text {threshold }}=1 / 12\right)$.

469 It can be seen that the forecast for Narrabeen still provides a useful estimate of shoreline recovery, even in this storm dominated environment (Figure 9a). Comparison with the measured data shows that unlike Perranporth the recovery At Narrabeen prior to the storm is high, lying entirely within

472 the upper end of the normal range (upper-green/amber boundary). This healthy recovery led to a healthy shoreline accretion prior to the inception of the Pasha Bulker storm sequence.

Notice also that the maximum storm erosion, indicated by the arrow, is in all of the pre-storm forecasts (Figures 9a-e), consistently on the erosional amber-red boundary, indicating that

477 shoreline displacement due to the Pasha Bulker storm sequence, like the Perranporth example, has 478 an event probability of $\approx 1 / 100$. Interestingly, shoreline positions and beach volumes along the New 479 South Wales coastline were not observed to have eroded excessively and certainly would have not 480 been at 1/100 year low after this storm sequence. It is important to make two important points here. 481 Firstly, this methodology is characterising shoreline displacement, rather than absolute shoreline 482 position. Whilst these two measures are similar, large erosion events should correlate with an 483 eroded shoreline, they are not the same thing. In this example, the pre-storm shoreline was quite 484 strongly pro-graded, thus, in spite of considerable storm erosion, the post-storm shoreline was not 485 excessively eroded. The second point to make is that classifications used here (normal, high and 486 extreme) will vary with the somewhat subjective choice of the event threshold ( $\left.P r_{\text {threshold }}\right)$. This 487 latter point is explored in the next section. 
489 Shoreline recovery after the Pasha Bulker storm is forecasted in Figure 9f. Like the post storm

490 Perranporth example, beach recovery is well forecasted at Narrabeen and is rapid, skirting both

491 the amber (high) red (extreme) intersection.

493 Sensitivity to the event threshold ( $\left.P r_{\text {threshold }}\right)$

494 Most extreme value analysis methods are sensitive to the threshold which defines an event. In the 495 previous examples, we have avoided a site-specific amplitude threshold, instead defining a 496 probability of occurrence threshold of 1 month in 1 year $\left(P r_{\text {threshold }}=1 / 12\right)$ to define a shoreline 497 displacement events which are likely to be outside the typical annual range. This forms the basis 498 of the traffic light characterisation presented here with outer limit of the high band limited to 1/100 499 event displacement $(\operatorname{Pr}=1 / 1200)$. Although, the event threshold has been intelligently selected, 500 based on the observation that shoreline time-series reach their minimum and maximum values 501 during just one month of the year, this value is still somewhat subjective.

503 In order to investigate the sensitivity to the event threshold probability, in figure 10 and 11 we 504 follow an identical methodology to that used to create figures 8 and 9 respectively, but have 505 adjusted the event probability threshold from the reasonable maximum value (1/12) to the likely 506 minimum extreme, 1 day in 1 year $\left(P r_{\text {threshold }}=1 / 365\right)$. Inspection figures 10 and 11 shows that the 507 main impact of reducing the event threshold is to broaden the green (normal) band of the traffic 508 light system with at the expense of the amber and red regions. Because of the shape of the P.D.F 509 functions, the limits of the high and extreme bands (amber and red) are only displaced outward a 510 relatively small amount. The resulting patterns are very similar but the characterisation of the 511 shoreline displacements in figures 10 and 11 are generally downgraded away from the extreme 512 classification and towards the normal band. It is not clear from the analysis exactly what the best 513 threshold setting is, application of the methodology to more storms and more sites will be required 514 in order to establish this. However, this test does serve to illustrate the sensitivity of the 515 classification (normal, high, extreme) to the threshold value. 


\section{5. Concluding Remarks}

518 A new methodology for forecasting shoreline displacement has been detailed in this contribution.

519 The methodology includes: generating multiple forcing time-series based on measured or modelled 520 wave data, the implementation of an established shoreline model [39] to drive a Monte Carlo 521 forecast of shoreline behaviour and characterising these shoreline responses with a generalised 522 extreme value (GEV) analysis. Results presented here indicate that it is indeed possible, at least 523 on these exposed, swash-aligned sites, to provide genuine forecasts of the limits of:

524 a) Shoreline recession due to the impact of a storm sequence.

525 b) Shoreline recovery after the passage of an extreme storm erosion events.

526 The methodology provides a probabilistic forecast (P.D.F.) of shoreline displacements, up to a 527 year in advance of the prediction start date and provided a simplistic 'traffic light' classification 528 based on the recurrence probability of an event. Shoreline forecasts are classified as normal (likely 529 to be observed in a typical year), high (events outside the typical annual recurrence probability) 530 and extreme (events outside the 1/100 event-recurrence probability).

532 Although the methodology has been tested on time-series of high-water shoreline displacement, it 533 could easily be transferred to the prediction of other definitions of the shoreline position or indeed 534 intertidal beach volumes. Here we use an established shoreline model, ShoreFor [39], but 535 acknowledge that the same methodology could be equally well implemented with other fast and 536 robust models of this genre. The present model is restricted to coasts dominated by cross-shore 537 sediment transport, but other modelling approaches could be combined with this general 538 forecasting methodology, including one-line models, in order to overcome these limitations.

540 In both applications presented here the models showed highly skilful hindcasts. This is an essential 541 pre-requisite of this forecasting approach. Poor model hindcasts are likely to lead to unreliable 542 forecasts. Here we recommend the model-data calibration coefficients ( $r$ ) (comparisons between 543 observations and model results) exceed 0.8 for accurate forecasts. Weaker correlations could lead 544 to forecasts that under-predict the magnitude of the shoreline response.

546 This contribution used measured shoreline data to calibrate the shoreline model. However, the 547 availability of shoreline data is not necessarily a limit to application of this particular model. 
548 Splinter et al., [15] showed that ShoreFor model free parameters can be estimated using easily available environmental parameters including wave climate and sediment properties.

A provisional sensitivity analysis shows that the minimum size of the pool of wave data required to produce accurate and consistent forecasts of shoreline response is approximately 15-years, although it is recommended that all the available data are used. In the simulations used here we

554 have implemented forecasts with both modelled (Perranporth) and a mixture of 555 measured/modelled (Narrabeen) wave data, both provided good forecasts of shoreline behaviour. 556 Since the use of commonly available modelled wave data seems to provide robust shoreline 557 predictions, the application of this methodology could potentially be quite widely used to the 558 prediction of extreme shoreline erosion and subsequent beach recovery.

The forecasts produce accurate representations of the observed shoreline behaviour. The characterisation of the shoreline behaviour (normal, high or extreme) is sensitive to the event probably threshold. Although the precise choice of event threshold remains somewhat ambiguous, provisional results suggest that the most appropriate descriptions of shoreline displacements were achieved by setting event recurrence threshold in the region $P r_{\text {threshold }} \approx 1 / 365$ to $1 / 12$. More widespread application of the methodology to different environments will be required in order to

568 Recent studies indicate that climatic indices can be skilfully predicted a year in advance [46]. The fact that climate indexes (e.g. NAO and ENSO) have been linked to storminess and shoreline change (e.g. Robinet et al., 2016), indicates that it may be possible to make more accurate predictions for the forthcoming year and perhaps beyond, if the synthetic waves used to force the

572 shoreline predictions were based only on past wave data with climate indexes similar to those 573 projected for the forecasting period.

\section{6. References}

[1] H.J. De Vriend, J., Zyserman, J., Nicholson, J. A. Roelvink, P. Pechon, and H.N. Southgate. Medium-term 2DH coastal area modelling, Coastal Engineering, 21, (1993), 193-225, doi:10.1016/0378-3839(93)90050-I. 
[2] J.A. Roelvink, J. A., \& I. Broker. Cross-shore profile models, Coastal Engineering, 21, (1993), 163-191, doi:10.1016/0378-3839(93)90049-E.

[3] L.C. Van Rijn, D.J.R. Walstra, B. Grasmeijer, J. Sutherland, S. Pan, \& J. P. Sierra. The predictability of cross-shore bed evolution of sandy beaches at the time scale of storms and seasons using processbased profile models, Coastal Eng., 47, (2003), 295-325, doi:10.1016/S03783839(02)00120-5

[4] M.A. Davidson, M. Van Koningsveld, A. de Kruif, J. Rawson, R. Holman, A. Lamberti, R. Medina, A. Kroon, and S. Aarninkhof. The CoastView project: Developing video-derived coastal state indicators in support of coastal zone management, Coastal Engineering, 54 (6-7), (2007), 463-475, doi:10.1016/j.coastaleng.2007.01.007.

[5] A. Kroon, M.A. Davidson, S.G.J. Aarninkhof, R. Archetti, C. Armaroli, M. Gonzalez, S. Medri,

[6] A.S. Farris and J.H. List. Shoreline as a proxy for subaerial beach volume change. Journal of Coastal Research 23(3), (2007), 740-748. A. Osorio, T. Aagaard, R.A. Holman, R. Spanhoff. Application of remote sensing video systems to coastline management problems, Coastal Engineering, 54(6-7), (2007), 493505, doi:10.1016/j.coastaleng.2007.01.004.

[10] A.B. Murray. Reducing model complexity for explanation and

[7] M.D. Harley, I.L. Turner, A.D. Short \& R. Ranasinghe. Assessment and integration of conventional, RTK-GPS and image-derived beach survey methods for daily to decadal coastal monitoring. Coastal Engineering 58(2), (2011), 194-205

[8] A. Robinet, B. Castelle, D. Idier, G. Le Cozannet, M. Deque \& E. Charles. Statistical modelling of Interannual shoreline change driven by North Atlantic climate variability spanning 2000-2014 in the Bay of Biscay. Geo-Mar. Lett. DOI 10.1007/s00367-016-0460-8. (2016).

[9] J.R. French, A. Payo, A.B. Murray, J. Orford, M. Eliot \& P. Cowell. Appropriate complexity for the prediction of coastal and estuarine geomorphic behaviour at decadal to centennial scales. Geomorphology. DOI: 10.1016/j.geomorph.2015.10.005, (2016). prediction. Geomorphology, 90(3), (2007), 178-191.

[11] M.A. Davidson, I.L. Turner. A behavioural template beach profile model for predicting seasonal to inter-annual shoreline evolution. Journal of Geophysical Research, 114, (2009), 1-21. 
610 [12] M.A. Davidson, R. P. Lewis, and I. L. Turner. Forecasting seasonal to multi-year shoreline change, Coastal Eng., 57, (2010), 620-629, doi:10.1016/j.coastaleng.2010.02.001.

612 [13] M.L. Yates, R.T. Guza \& W.C. O’Reilly. Equilibrium shoreline response: Observations and modeling, J. Geophys. Res., 114, C09014, doi:10.1029/2009JC005359, (2009).

614 [14] M.L. Yates, R.T. Guza, W.C. O’Reilly, J.E. Hansen \& P.L. Barnard. Equilibrium shoreline response of a high wave energy beach, J. Geophys. Res., 116, C04014, doi:10.1029/2010JC006681. (2011).

[15] K.D. Splinter, I.L. Turner, M.A. Davidson, P. Barnard, B. Castelle \& J. Oltman-Shay. A generalized equilibrium model for predicting daily to inter-annual shoreline response. Journal of Geophysical Research: Earth Surface, (2014), 1936-1958.

[16] H. Hanson \& N. Kraus. Generalized model for simulating shoreline change, Report 1, Technical Reference, Tech. Rep., U. S. Army Engineer Waterways Experiment Station; Coastal Engineering Research Center (U. S.); United States. Army. Corps of Engineers, (1989).

[17] H. Hanson. GENESIS: a generalized shoreline change model. Journal of Coastal Research 5 (1), (1989), 1-27. (I): Basis Function Methods. Journal of Coastal Research: 25(2), (2009), 366 - 379. 
[23] P. Ruggiero, J. List, D. Hanes \& J. Eshleman. Probabilistic Shoreline Change Modelling. Proc. 30th International Conference on Coastal Engineering, September 2006, San Diego, CA. (2006).

[24] D. E. Reeve, A. Pedrozo-Acuña, M. Spivack. Beach memory and ensemble prediction of shoreline evolution near a groyne. Coastal Engineering, 86, April 2014, (2014), 77-87.

[26] I.L. Turner, M.D. Harley, A.D. Short, J.A. Simmons, M.A. Bracs, M.S. Phillips \& K.D.

[25] M.A. Davidson, D.A. Huntley, R.A. Holman \& K. George. The evaluation of large-scale $(\mathrm{km})$ intertidal beach morphology on a macrotidal beach using video images. Proceedings

[28] G. Dodet, X. Bertin, \& R. Taborda. Wave climate variability in the North-East Atlantic Ocean over the last six decades. Ocean Modelling 31, (2010), 120-131. Splinter. A multi-decade dataset of monthly beach profile surveys and inshore wave forcing at Narrabeen, Australia. Scientific Data 3, Article number: 160024. doi:10.1038/sdata.2016.24, (2016).

[27] M.R. Gourlay. Beach and dune erosion tests. Rep. M935/M936. Delft Hydraulics Laboratory, Delft, Netherlands. (1968).

[29] G. Masselink, M. Austin, T. Scott, T. Poate \& P. Russell. Role of wave forcing, storms and NAI in outer bar dynamics on a high energy, macro-tidal beach. Geomorphology, 226, (2014), 76-93.

[30] S. Prodger, P.E. Russell, M.A. Davidson \& T. Scott. Understanding and predicting the temporal variability of sediment grain size characteristics on high-energy beaches. Marine Geology Volume 376, 1 June 2016, (2015), 109-117.

[31] G. Masselink \& A.D. Short. The effect of tidal range on intertidal beach morphology: a conceptual model. J. Coastal Research 9, (1993), 785-800.

[32] T. Thomas, M.R. Phillips, A.T. Williams \& R.E. Jenkins. Medium-scale behaviour of adjacent embayed beaches: influence of low energy external forcing. Applied Geography 32, (2012), 265-280.

[33] A.D. Short \& N.L. Trenaman. Wave climate of the Sydney region, an energetic and highly variable ocean wave regime. Australian Journal of Marine and Freshwater Research 43, (1992), 765-791. 
[34] M.D. Harley, I.L. Turner, A.D. Short \& R. Ranasinghe. Interannual variability and controls of the Sydney wave climate. International Journal of Climatology, 1335, (2010), 13221335

[35] D. Lord \& M. Kulmar. The 1974 storms revisited: 25-years experience in ocean wave measurement along the south-east Australian coast. In Proceedings, International Coastal Engineering Conference, Sydney, (2000), 559-572.

[36] R. Ranasinghe, R. Mcloughlin, A.D. Short \& G. Symonds. The Southern Oscillation Index, wave climate, and beach rotation. Marine Geology, 204, (2004), 2-7.

[37] G. Masselink, T. Scott, T. Poate, P. Russell, M. Davidson \& D. Conley. The extreme 2013/2014 winter storms: hydrodynamic forcing and coastal response along the southwest coast of England. Earth Surface Processes and Landforms. DOI: 10.1002/esp.3836. (2014).

[38] M.D. Harley, I.L. Turner, K. D. Splinter, M.S. Phillips \& J.A. Simmons. Beach response to Australian East Coast Lows: a comparison between the 2007 and 2015 events, NarrabeenCollaroy Beach. Journal of Coastal Research. SI 75, (2016), 388-392

[39] M.A. Davidson, K.D. Splinter \& I.L. Turner. A simple equilibrium model for predicting shoreline change. Coastal Engineering, 73, (2013), 191-202. Available at: http://www.sciencedirect.com/science/article/pii/S0378383912001676

[40] L.D. Wright, A.D. Short \& M.O. Green. Short-term changes in the morphodynamic states of beaches and surfzones: an empirical predictive model. Marine Geology 62, (1985), 339364.

[41] L.E. Borgman, N.W. Scheffner. Simulation of Time Sequences of Wave Height, Period, and Direction. Technical Report DRP-91-2,54. US Army Corps of Engineers, Washington, (1991).

[42] S. Kotz, \& S. Nadarajah. Extreme Value Distributions: Theory and Applications. London: Imperial College Press. (2000).

[43] E.J. Gumbel. "Statistics of Extremes." Columbia University Press, New York. (1958).

[44] R.A. Fisher \& L.H.C. Tippett. Limiting forms of the frequency distribution of the largest and smallest member of a sample." Proc. Cambridge Philosophical Society 24, (1928), 180190. 
[45] W. Weibull. A statistical distribution function of wide applicability, J. Appl. Mech.-Trans. ASME 18(3), (1951), 293-297.

[46] Z. Liu \& H. Burcharth. Encounter Probability of Individual Wave Height. Coastal Engineering 1998, (1999), 1027-1038. doi: 10.1061/9780784404119.076

[47] N. Dunstone, D. Smith, A. Scaife, L. Hermanson, R. Eade, N. Robinson, M. Andrews \& J. Knight. Skilful predictions of the winter North Atlantic Oscillation one year ahead.

\section{Acknowledgements}

708 A special thanks to Gerd Masselink, Paul Russel, Tim Scott, Tim Poate, Martin Austin, Kit Stokes, 709 Peter Ganderton and all others who contributed to the Perranporth data set included in this paper.

710 This research was funded by the Australian Research Council Discovery Grant DP150101339.

711 Mark Davidson would like to extend a special thanks to Water Research Laboratory, School of 712 Civil and Environmental Engineering, UNSW Sydney for additional funding and hosting his visits 713 to work with the Australian team and to all of the staff at the Water Resources Laboratory for 714 making this such a pleasant and productive sabbatical.

\section{List of Figures}

717 Figure 1. Location map for a) Perranporth, Cornwall, UK and b) Narrabeen, NSW, Australia.

718 Figure 2. Monthly ensemble averages offshore wave power (top), dimensionless fall velocity 719 (middle) and shoreline displacement (bottom) for Perranporth, UK (left) and Narrabeen, 720 Australia (right). Ensemble means are presented with $95 \%$ confidence interval bars in all cases. 721 The number of years of wave data in the ensembles for Perranporth and Narrabeen are 63 and 36 years respectively. For both sites over 8-years of shoreline data have been ensemble

724 Figure 3. The top two plots ( $\mathrm{a}$ and $\mathrm{b}$ ) show the 9-year wave power and associated shoreline 725 displacements (mean high-tide contour) recorded at Perranporth. Also shown are the model 726 calibrations hindcasts and the unseen storm-validation hindcasts for the 2013/14 storms. The 727 lower two plots are the equivalent series for Narrabeen (c and d). Notice that the Pasha Bulker 728 June 2007 storm series has been used for the unseen model validation. 
729 Figure 4. An example of the synthetic forcing time-series (wave power [top] and dimensionless 730 fall velocity [bottom]) used to drive the shoreline forecast. This is an annual forecast starting 731 on the $1^{\text {st }}$ October 2013 (dotted vertical line). Noticed that each record starts with 6-years of 732 observed antecedent measurements to which 1000 different, year-long, synthetic series are 733 appended.

734 Figure 5 This figure shows the 1000 resulting shoreline estimates generated from applying the 735 forcing series in figure 4 to the ShoreFor model. The ensemble-mean tendency is shown by the solid black line, illustrating the seasonal trend in shoreline erosion and accretion. The letters and arrow represent the shoreline data shown in the figures 6 a to $f$. $\left(P r_{\text {threshold }}=1 / 12\right)$

Figure 6. Histograms of the shoreline data for different months after the start of the forecast $t_{0}=1$ October 2013. All shoreline positions are relative to the starting location at $t_{0}$. Also shown is the extreme value analysis probability density function fitted to the data (solid black line). The traffic light system represents the normal (green), high (amber) and extreme range (red). $\left(P r_{\text {threshold }}=1 / 12\right)$

Figure 7. Sensitivity analysis on the duration of the wave pool used to generate the synthetic wave time-series. Data are shown with error bars representing $+/$ - two standard deviations in the $400 \mathrm{~m}$ longshore shoreline contour, which have need averaged to give the shoreline estimates [open circles]. Notice that the classification of the storm remains unchanged until the wave pool is decimated to 10-years. $\left(P r_{\text {threshold }}=1 / 12\right)$

Figure 8: Six forecasts of shoreline displacements for Perranporth Beach, UK (seasonally dominated system), starting during the pre-storm recovery period in May and progressing in 2mothly intervals until the post-storm recovery period in March 2014. The arrow indicates the maximum shoreline recession due to the storm in each case. $\left(\operatorname{Pr}_{\text {threshold }}=1 / 12\right)$

Figure 9 Forecasted shoreline response for Narrabeen, Australia (storm dominated system). Forecasts start with $t_{0}$ at the pre-storm recovery phase in October 2006 and progress at two759 monthly intervals through the main storm sequence in June 2007 and to the post-storm recovery starting in August 2007. $\left(P r_{\text {threshold }}=1 / 12\right)$

Figure 10. Similar Perranporth example plot to Figure 8 with a modified event probability threshold of $P r_{\text {threshold }}=1 / 365$.

Figure 11. Similar Narrabeen example plot to Figure 9 with a modified event probability threshold of $P r_{\text {threshold }}=1 / 365$. 


\section{List of Tables}

762 Table 1. Comparative data/site characteristics for Perranporth and Narrabeen, including annual

763 average deep-water wave characteristics and sediment properties. $\sigma_{\Omega 360} / \sigma_{\Omega 30}$ is a seasonality

764 index (Splinter et al., [15]) describing the ratio of the average annual to monthly standard

765 deviation in dimensionless fall velocity, higher values indicating increased seasonality. Notice

766 that seasonality at Perranporth is some $20 \%$ higher than Narrabeen and that dimensionless fall

767 velocities are double a Perranporth indicating more dissipative beach states. 


\begin{tabular}{|l|c|c|c|c|c|c|c|c|c|c|}
\hline Site & $\begin{array}{c}H_{s} \\
{[\mathrm{~m}]}\end{array}$ & $\begin{array}{c}T_{p} \\
{[\mathrm{~m}]}\end{array}$ & $\boldsymbol{\Omega}$ & $\begin{array}{c}\boldsymbol{D}_{50} \\
{[\mathrm{~mm}]}\end{array}$ & $\begin{array}{c}\omega \\
{[\mathrm{m} / \mathrm{s}]}\end{array}$ & $\begin{array}{c}\sigma \Omega 3360 \\
/ \sigma \Omega 30\end{array}$ & $\begin{array}{c}\text { Survey } \\
\text { Method } \\
\text { (interval) }\end{array}$ & $\begin{array}{c}\text { Wave } \\
\text { data } \\
{[\text { Yrs }]}\end{array}$ & $\begin{array}{c}\text { Wave } \\
\text { Measurement } \\
\text { (type) }\end{array}$ & Depth \\
\hline Perranporth & 1.98 & 8.3 & 5.30 & 0.33 & 0.04 & 1.22 & $\begin{array}{c}\text { Survey } \\
\text { (monthly) }\end{array}$ & 63 & $\begin{array}{c}\text { Sevenstones } \\
\text { (modelled) }\end{array}$ & 73 \\
\hline Narrabeen & 1.62 & 9.6 & 3.67 & 0.40 & 0.05 & 1.07 & $\begin{array}{c}\text { Video } \\
\text { (weekly) }\end{array}$ & 36 & $\begin{array}{c}\text { Sydney } \\
\text { (measured) }\end{array}$ & 74 \\
\hline
\end{tabular}

Table 1. Comparative data/site characteristics for Perranporth and Narrabeen, including annual average deep-water wave characteristics and sediment properties. $\sigma \Omega 360 / \sigma \Omega 30$ is a seasonality index (Splinter et al., 2014) describing the ratio of the average annual to monthly standard deviation in dimensionless fall velocity, higher values indicating increased seasonality. Notice that seasonality at Perranporth is some $20 \%$ higher than Narrabeen and that dimensionless fall velocities are double a Perranporth indicating more dissipative beach states. 
a)

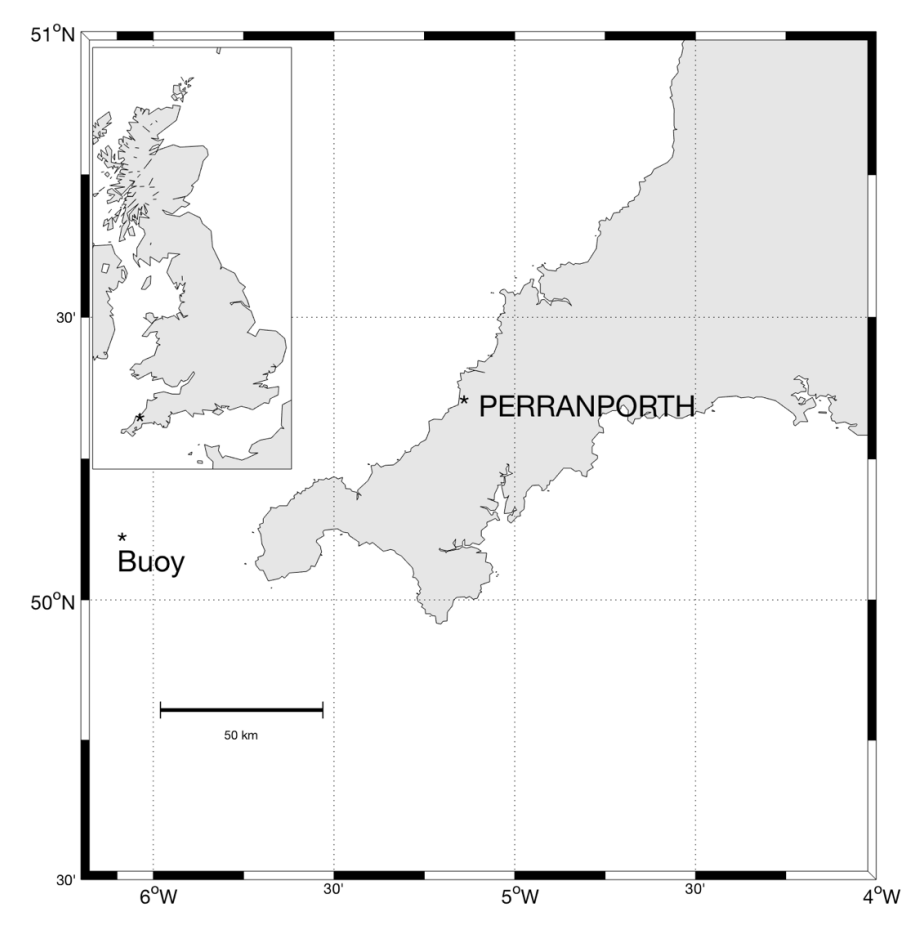

b)

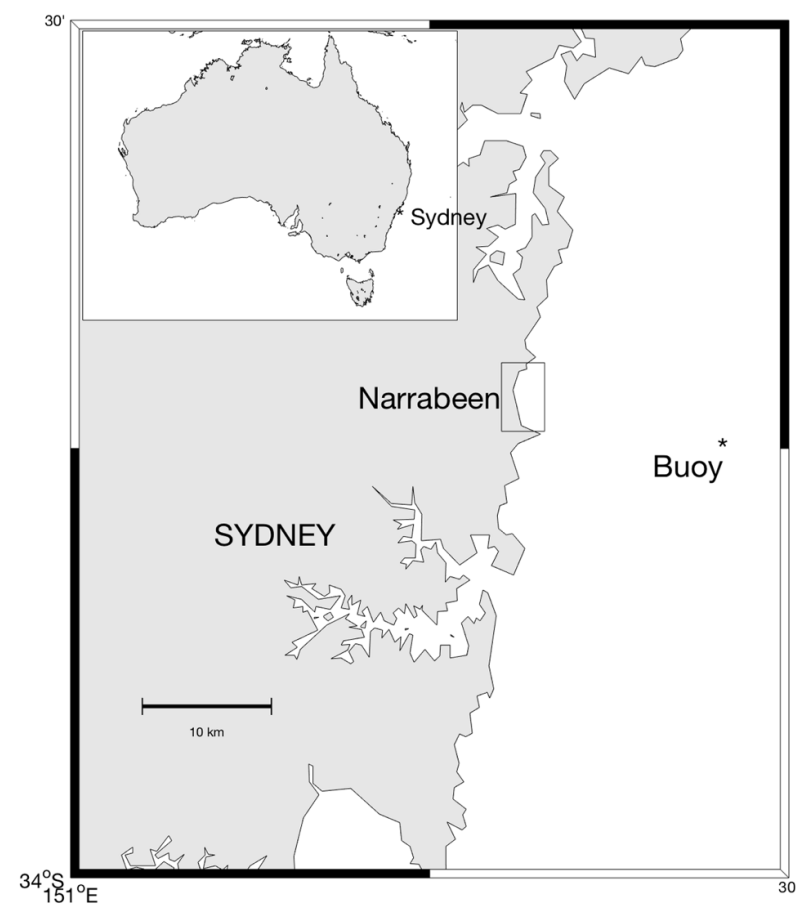

Figure 1. Location map for a) Perranporth, Cornwall, UK and b) Narrabeen, NSW, Australia. 
a)

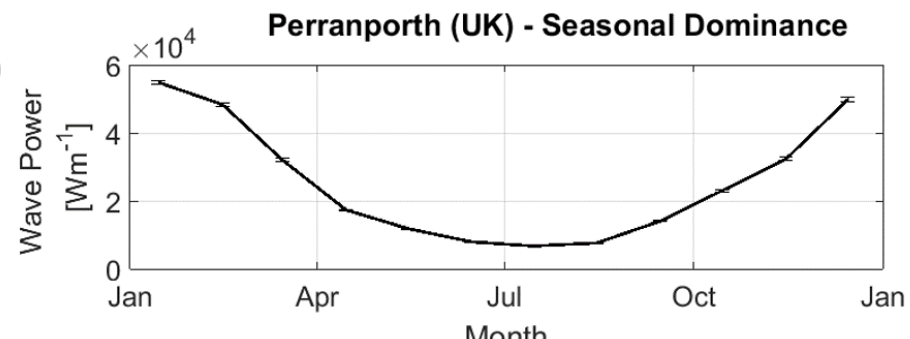

c)

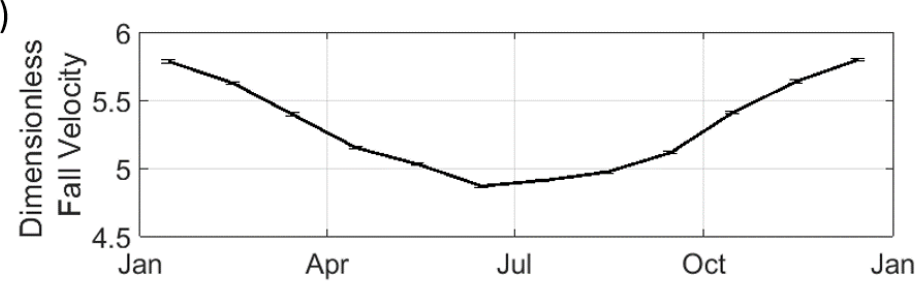

e)

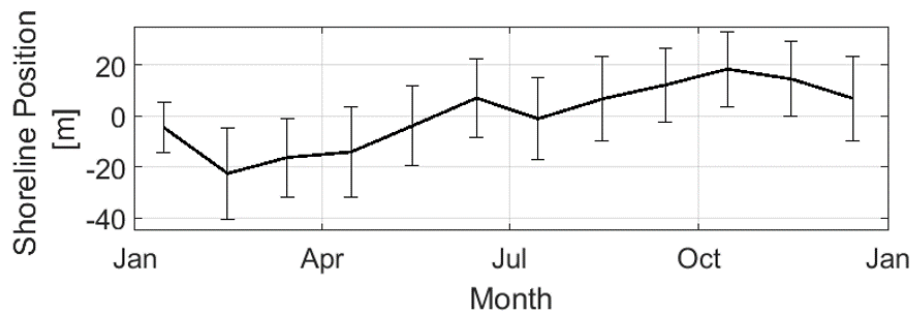

b)

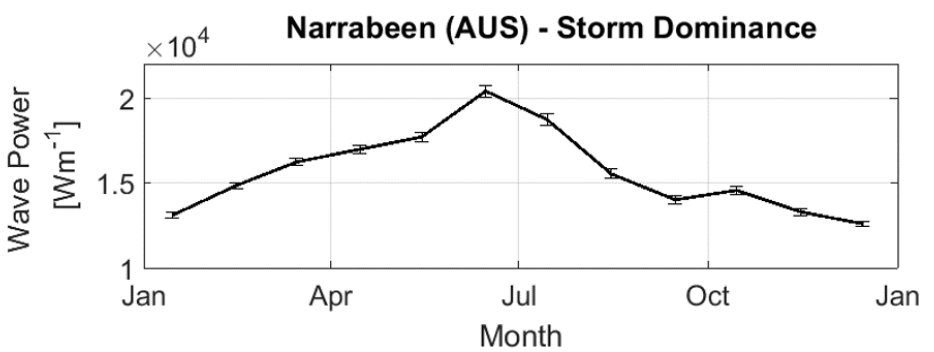

d)

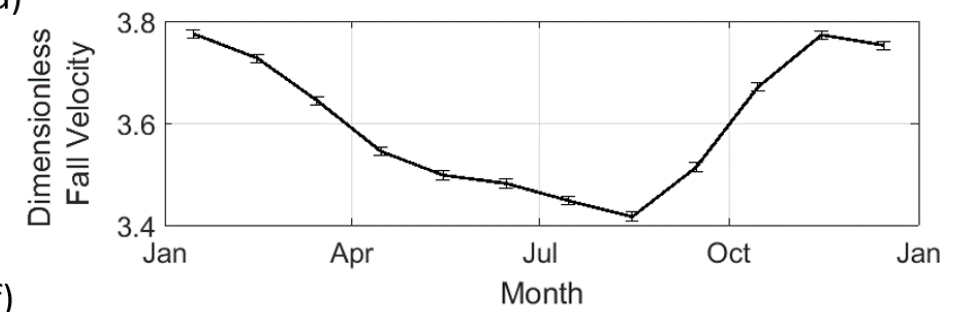

f)

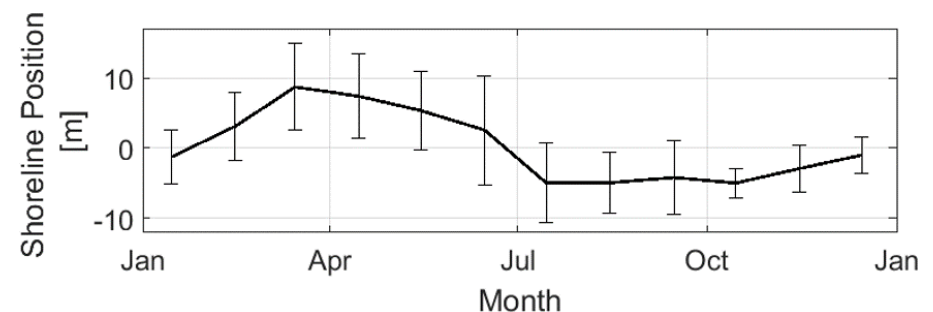

Figure 2. Monthly ensemble averages offshore wave power (top), dimensionless fall velocity (middle) and shoreline displacement (bottom) for Perranporth, UK (left) and Narrabeen, Australia (right). Ensemble means are presented with $95 \%$ confidence interval bars in all cases. The number of years of wave data in the ensembles for Parranporth and Narrabeen are 63 and 36 years respectively. For both sites over 8-years of shoreline data have been ensemble averaged. 

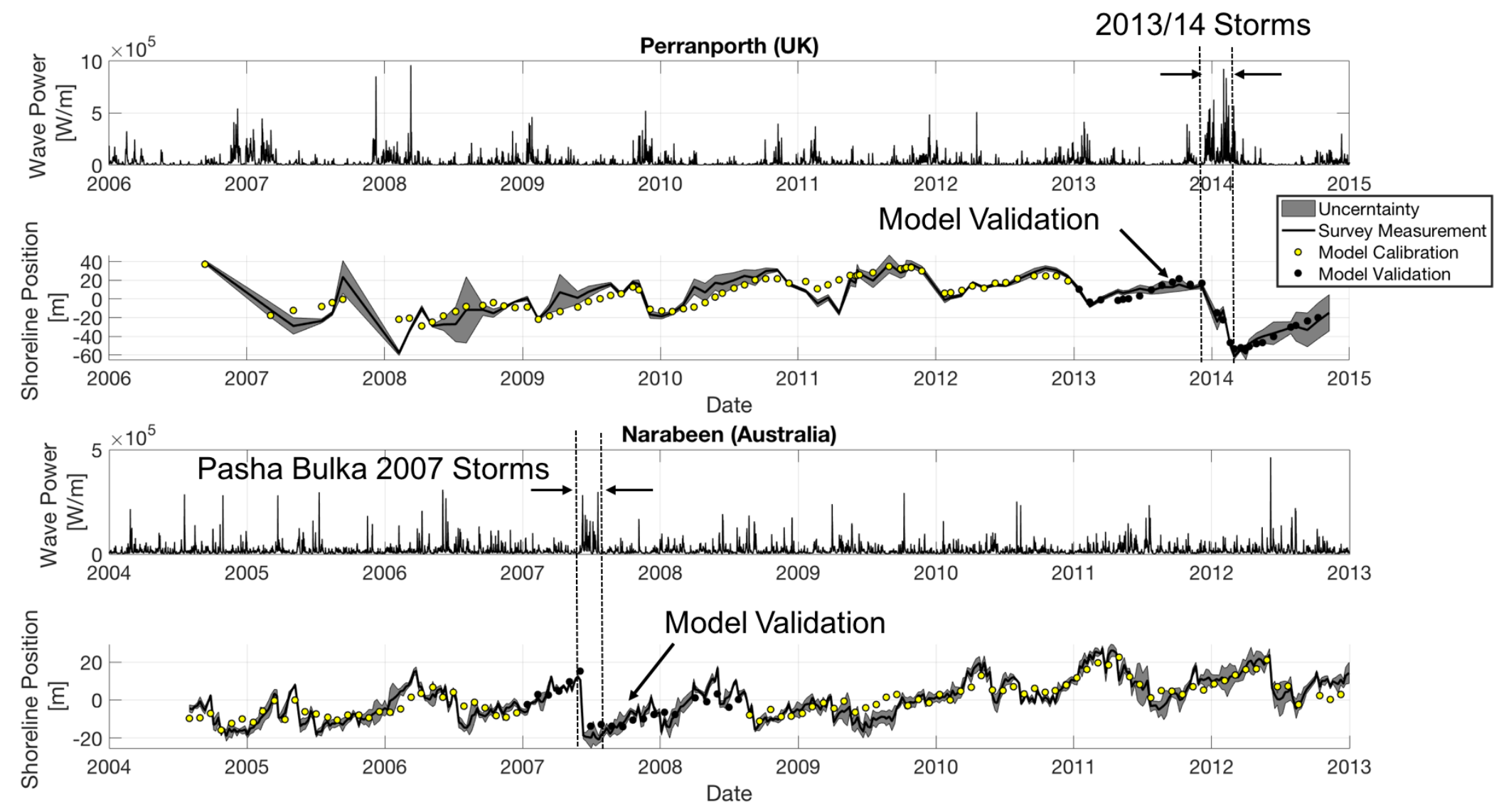

Figure 3. The top two plots ( $a$ and $b$ ) show the 9-year wave power and associated shoreline displacements (mean hightide contour) recorded at Perranporth. Also shown are the model calibrations hindcasts and the unseen stormvalidation hindcasts for the 2013/14 storms. The lower two plots are the equivalent series for Narrabeen (c and d). Notice that the Pasha Bulker June 2007 storm series has been used for the unseen model validation. 
1000 Simulated

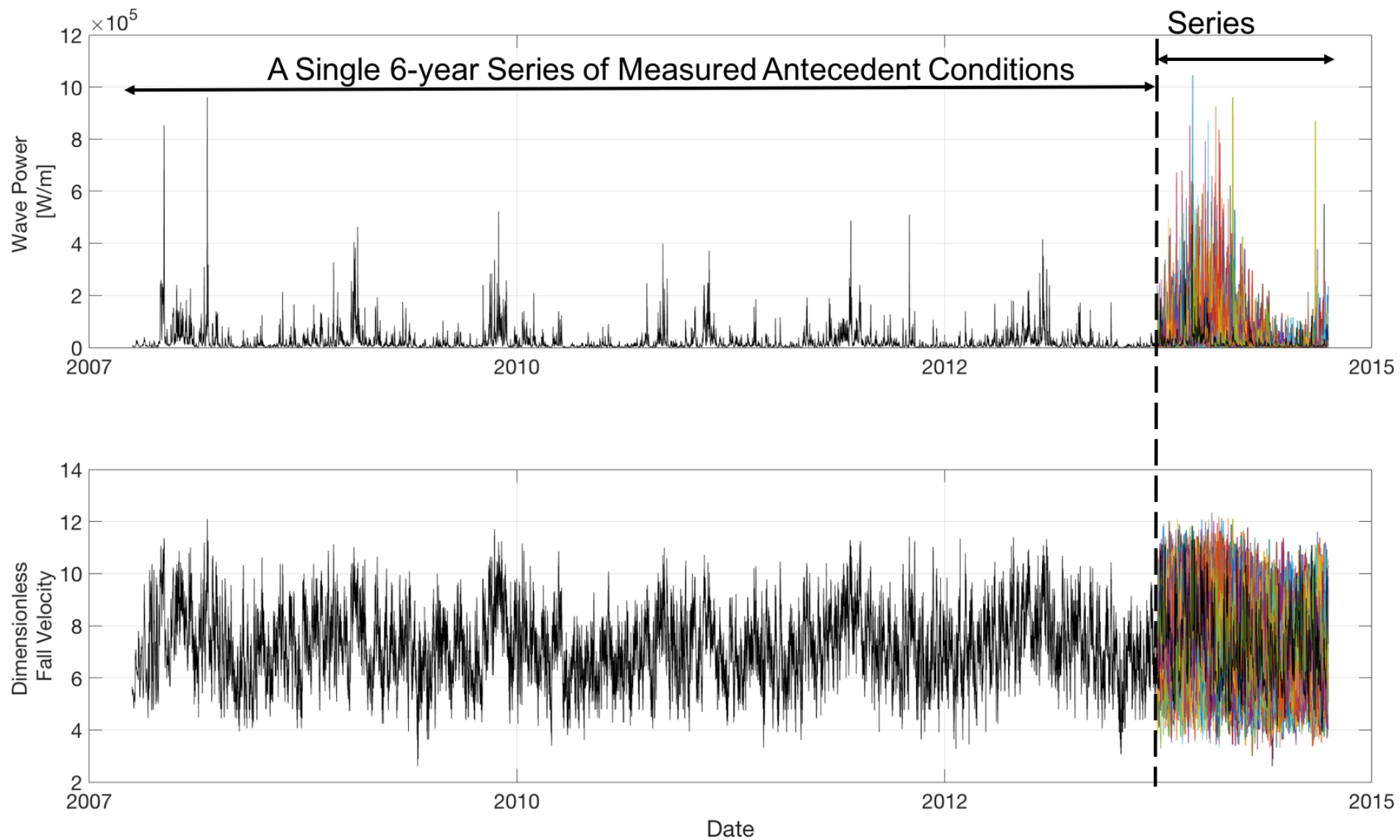

Figure 4. An example of the synthetic forcing time-series (wave power [top] and dimensionless fall velocity [bottom]) used to drive the shoreline forecast. This is an annual forecast starting on the $1^{\text {st }}$ October 2013 (dotted vertical line). Noticed that each record starts with 6-years of observed antecedent measurements to which 1000 different, year-long, synthetic series are appended. 


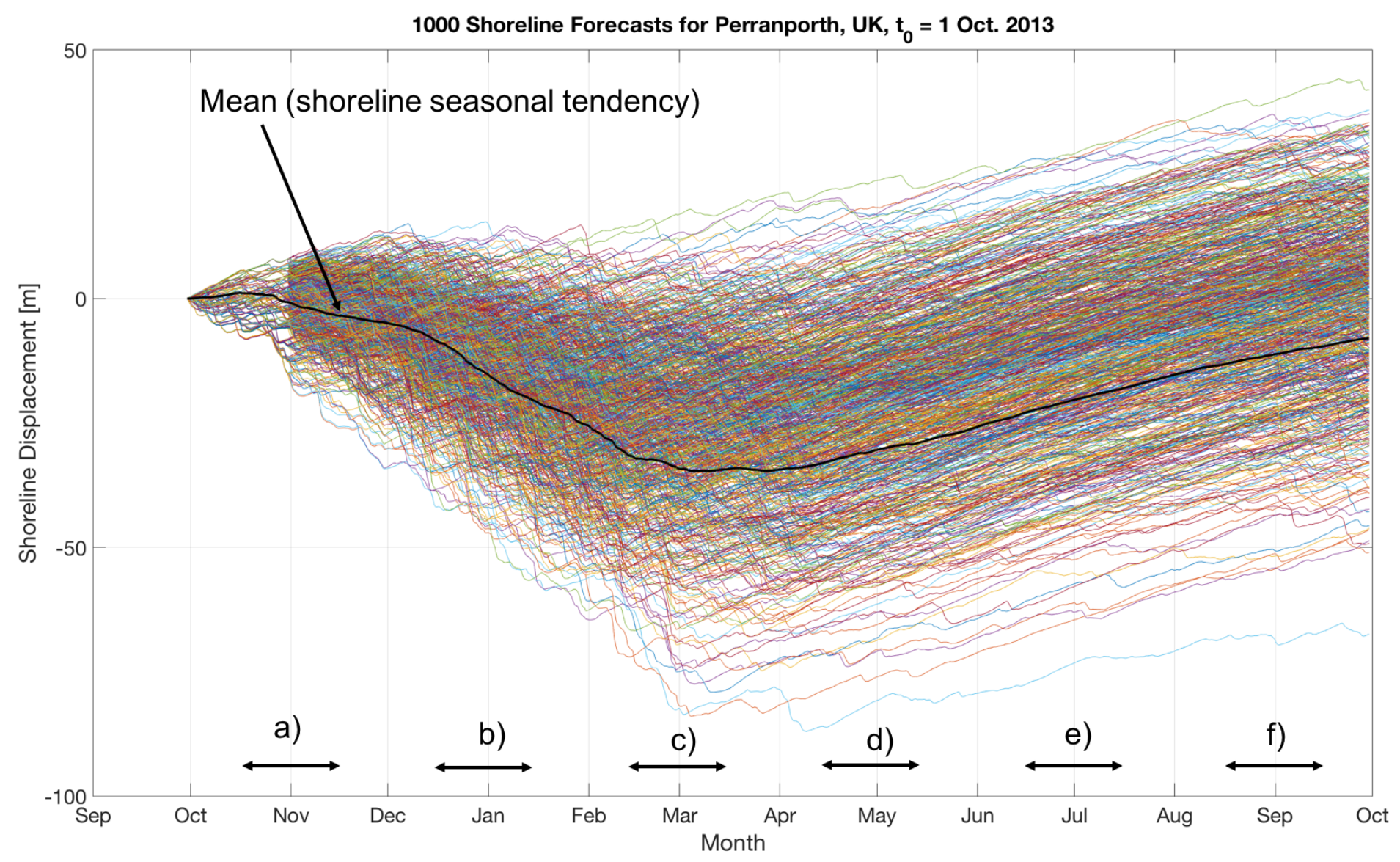

Figure 5 This figure shows the 1000 resulting shoreline estimates generated from applying the forcing series in figure 4 to the ShoreFor model. The ensemble-mean tendency is shown by the solid black line, illustrating the seasonal trend in shoreline erosion and accretion. The letters and arrow represent the shoreline data shown in the figures 6 a to $f$.

$\left(P r_{\text {threshold }}=1 / 12\right)$ 

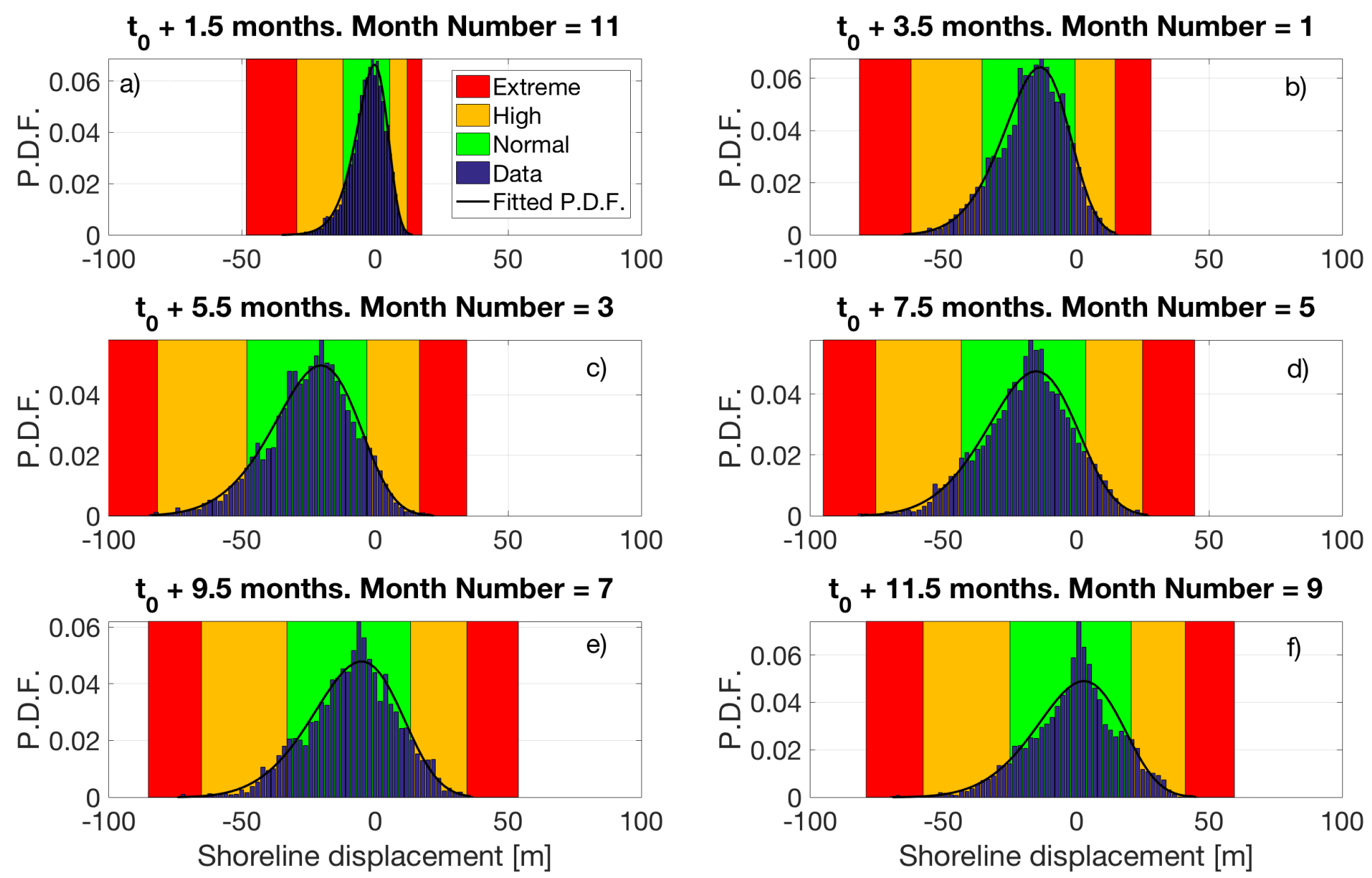

Figure 6. Histograms of the shoreline data for different months after the start of the forecast $t_{0}=1$ October 2013. All shoreline positions are relative to the starting location at $t_{0}$. Also shown is the extreme value analysis probability density function fitted to the data (solid black line). The traffic light system represents the normal (green), high (amber) and extreme range (red). $\left(P r_{\text {threshold }}=1 / 12\right)$. 

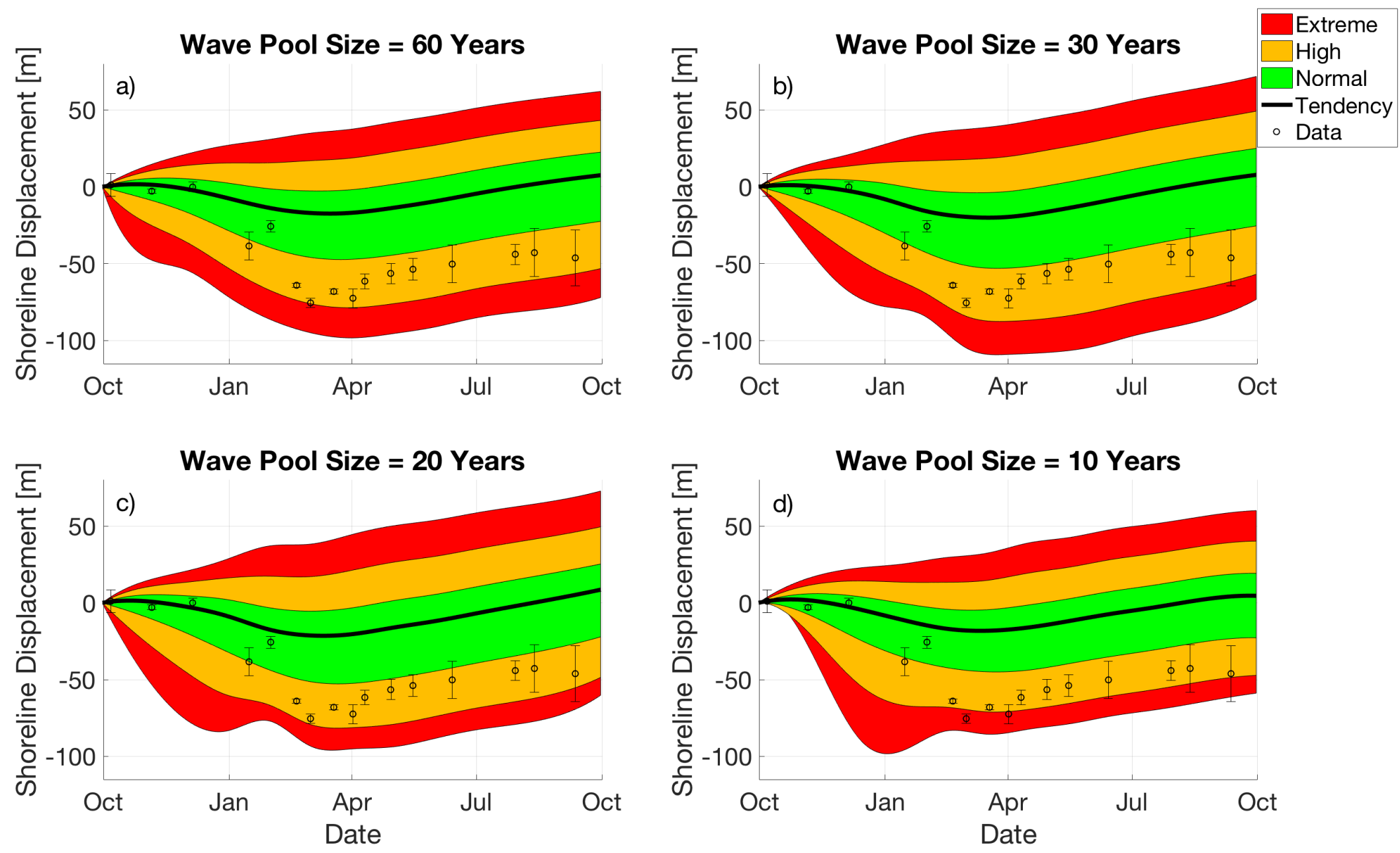

Figure 7. Sensitivity analysis on the duration of the wave pool used to generate the synthetic wave time-series. Data are shown with error bars representing +/- two standard deviations in the 400m longshore shoreline contour, which have need averaged to give the shoreline estimates [open circles]. Notice that the classification of the storm remains unchanged until the wave pool is decimated to 10 -years. $\left(P r_{\text {threshold }}=1 / 12\right)$ 

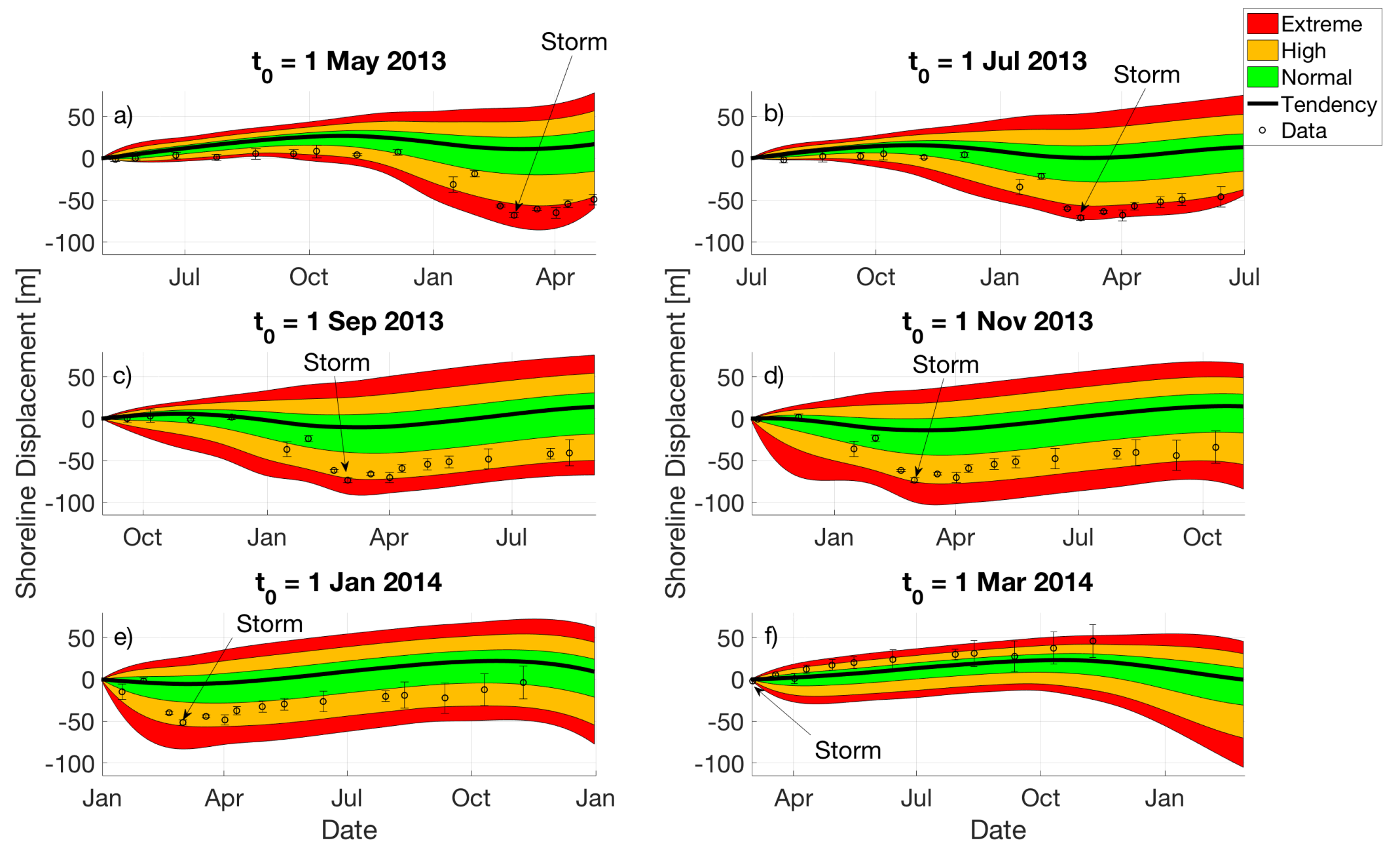

Figure 8: Six forecasts of shoreline displacements for Perranporth Beach, UK (seasonally dominated system), starting during the pre-storm recovery period in May and progressing in 2-mothly intervals until the post-storm recovery period in March 2014. The arrow indicates the maximum shoreline recession due to the storm in each case. $\left(P r_{\text {threshold }}=1 / 12\right)$. 

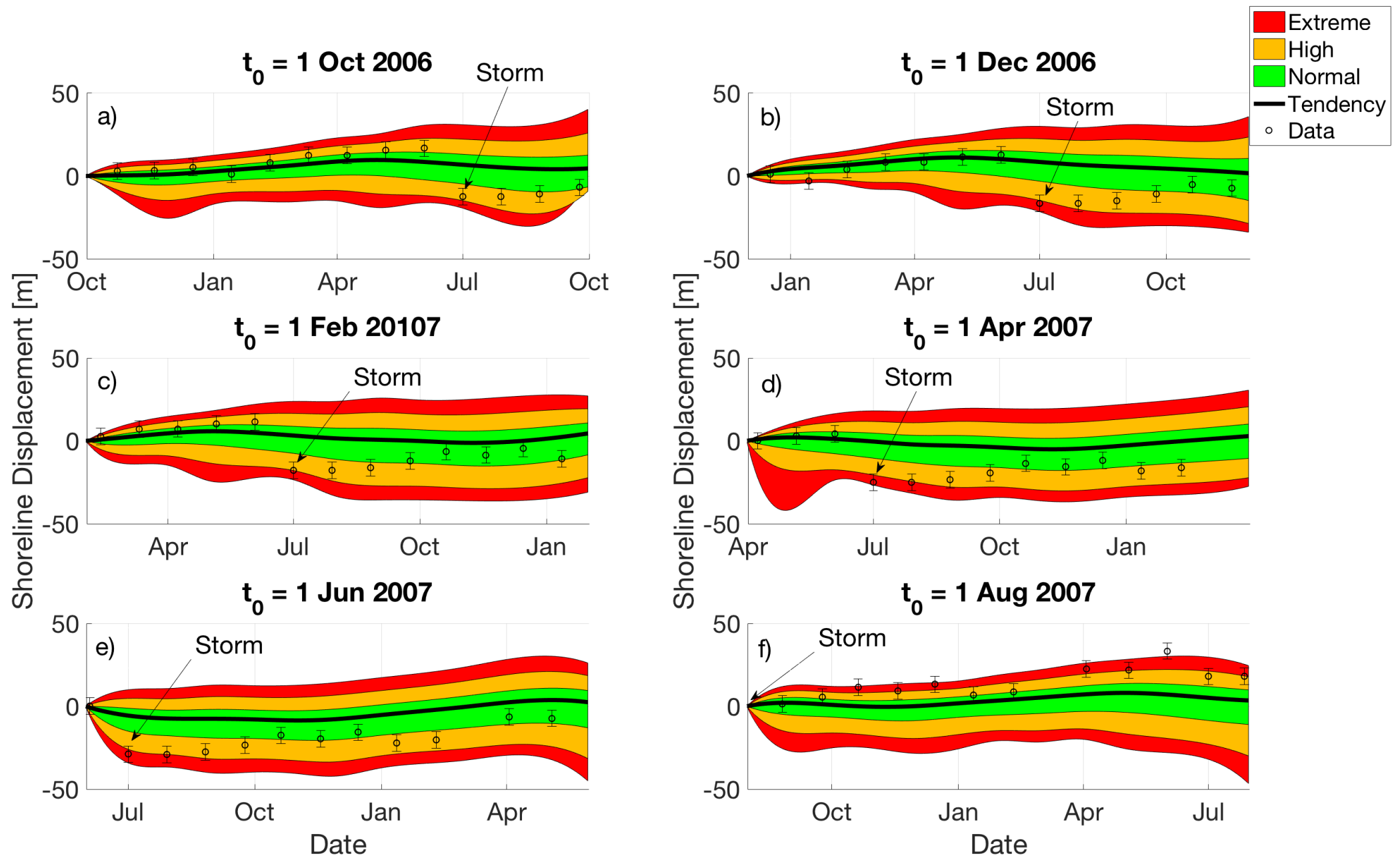

Figure 9 Forecasted shoreline response for Narrabeen, Australia (storm dominated system). Forecasts start with $\mathrm{t}_{0}$ at the pre-storm recovery phase in October 2006 and progress at two-monthly intervals through the main storm sequence in June 2007 and to the post-storm recovery starting in August 2007. $\left(P r_{\text {threshold }}=1 / 12\right)$. 

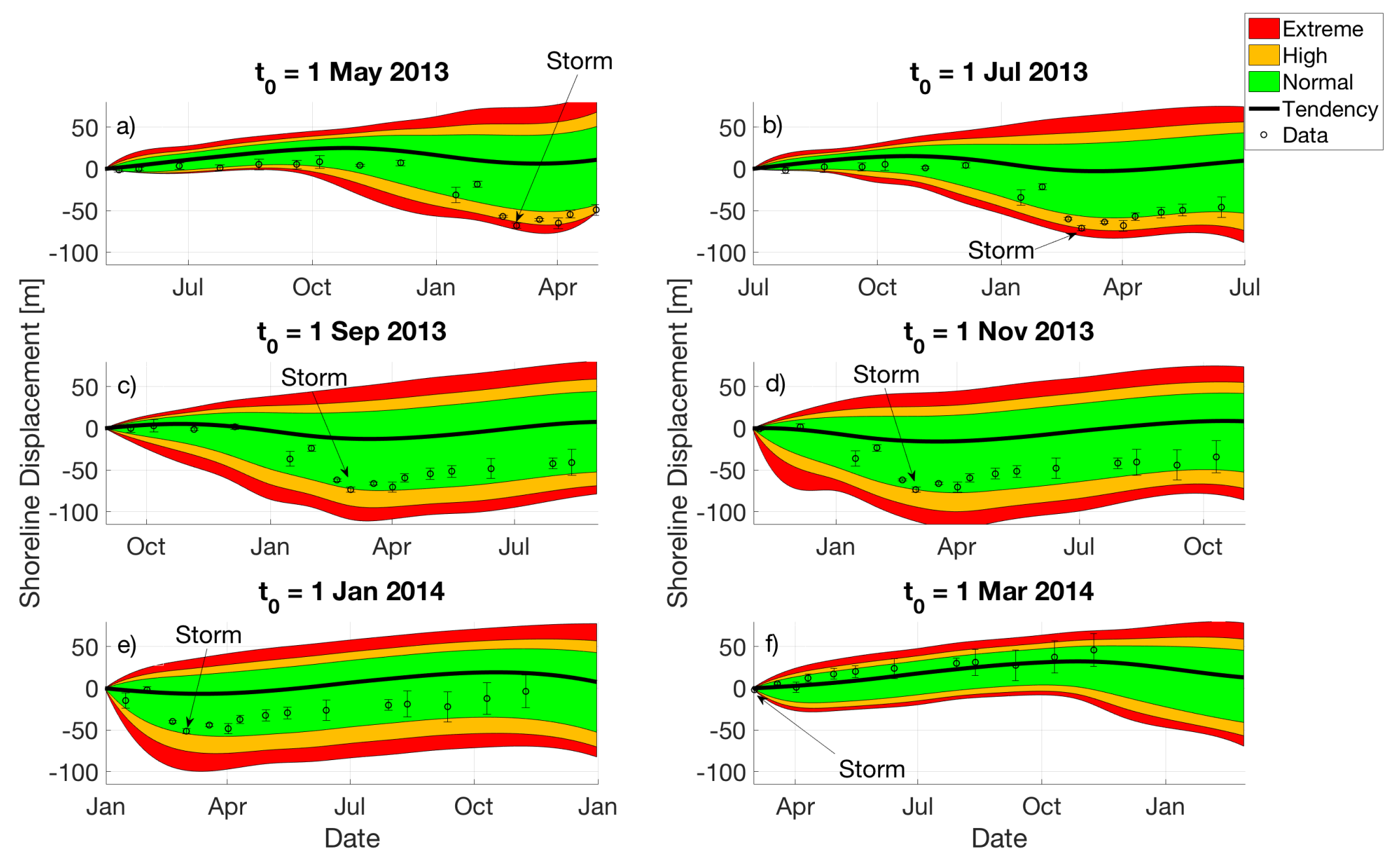

Figure 10. Similar Perranporth example plot to Figure 8 with a modified event probability threshold of $\operatorname{Pr}_{\text {threshold }}=1 / 365$. 

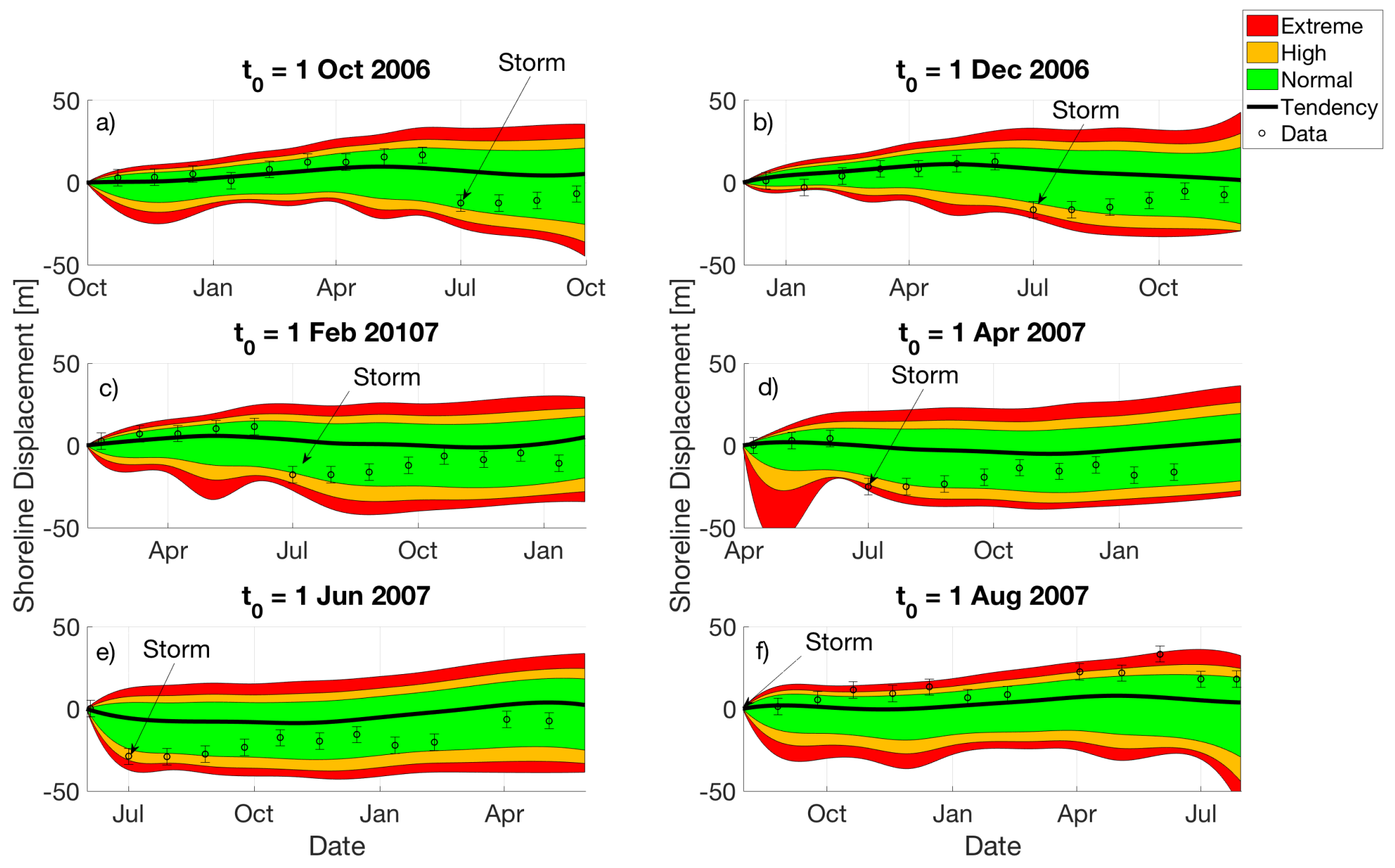

Figure 11. Similar Narrabeen example plot to Figure 9 with a modified event probability threshold of $P r_{\text {threshold }}=1 / 365$. 